\title{
THE PHARMACOLOGICAL BASIS OF THE CURCUMIN NUTRACEUTICAL USES: AN UPDATE
}

\author{
D. Canistro ${ }^{1,9}$, A. Chiavaroli' 2,9 , D. Cicia ${ }^{3,9}$, F. Cimino 4,9, D. Currò 5,9, M. Dell'Agli6,9, C. \\ Ferrante $^{2,9}$, L. Giovannelli 7,9 , S. Leone 2,9 , G. Martinelli6,9, L. Milella ${ }^{8,9}$, E. Pagano ${ }^{3,9}$, S. \\ Piazza $^{6,9}$, M. Ponticelli ${ }^{8,9}$, L. Recinella ${ }^{2,9}$, S. Ristori ${ }^{7,9}$, E. Sangiovanni ${ }^{6,9}$, A. Smeriglio ${ }^{4,9}$, \\ A. Speciale ${ }^{4,9}$, D. Trombetta ${ }^{4,9}$, F. Vivarelli ${ }^{1,9}$
}

1'Department of Pharmacy and Biotechnology, University of Bologna, Bologna, Italy 2Department of Pharmacy, Medicinal Plant Unit (MPU), Giardino dei Semplici Botanic Garden, G. d'Annunzio University of Chieti-Pescara, Chieti, Italy ${ }^{3}$ Department of Pharmacy, Federico II Naples University, Naples, Italy ${ }^{4}$ Department of Chemical, Biological, Pharmaceutical and Environmental Sciences, University of Messina, Messina, Italy

${ }^{5}$ Department of Security and Bioethics, Pharmacology Section, Università Cattolica del Sacro Cuore, Rome, Italy ${ }^{6}$ Department of Pharmacological and Biomolecular Sciences, University of Milan, Milan, Italy ${ }^{7}$ NEUROFARBA, University of Florence, Florence, Italy ${ }^{8}$ Department of Science, University of Basilicata, Potenza, Italy ${ }^{9}$ Working Group Pharmacognosy, Phytotherapy and nutraceuticals of the Italian Society of Pharmacology (SIF), Milan, Italy

E-mail: mario.dellagli@unimi.it

Doi: $10.36118 /$ pharmadvances.2021.06

\section{SUMMARY}

Curcumin is the major phytoconstituent found in the rhizomes of Curcuma longa L. Preparations derived from the rhizome of the plant, referred as turmeric, have been used for centuries in the traditional Indian system of medicine. The recent literature has shown curcumin as one of the most interesting pleiotropic nutraceuticals capable of interacting with different molecular targets involved in chronic diseases. The present review summarizes and critically discusses the very recent literature published between 2018 and 2021. We focused on the preclinical pharmacological actions of curcumin in relation to its possible clinical application in several pathophysiological states and disturbances including inflammation and pain, as well as metabolic, cardiovascular, dermatological, and central nervous system diseases. The most relevant molecular targets of curcumin, such as transcription factors, pro-inflammatory mediators, enzymes, and protein kinase as well as pharmacokinetics in humans are also reviewed.

\section{Key words}

Curcumin; nutraceutical; Pharmacology; botanicals, natural products.

\section{Impact statement}

An update of the pharmacological and nutraceutical potential of curcumin emerging by preclinical and meta-analysis studies. 


\section{INTRODUCTION}

Turmeric (Curcuma longa L., Zingiberaceae Family) is native to India, the world's largest producer and exporter; however, it is currently also grown in Southeast Asia, Latin America, and China (1). The drug consists of turmeric rhizomes containing a percentage of curcuminoid ranging between 2-9\% depending on the origin, soil conditions, and climate (2). Under the name of "curcuminoids" are grouped three diarylheptanoids (diferuloylmethane derivatives), which include curcumin, demethoxycurcumin (DMC), bisdemethoxycurcumin (BMC), and other less abundant secondary metabolites (3) (figure 1). In particular, curcumin is the major phytoconstituent found in the rhizomes of Curcuma longa $\mathrm{L}$. since it accounts for $77 \%$, while DMC and BMC for $17 \%$ and $3-6 \%$ approximately $(1,4)$; curcumin was extracted for the first time in a pure crystalline form in 1870 (5). Nonetheless, curcumin, DMC, and BMC have been isolated from various Curcuma spp., including Curcuma amada Roxb., Curcuma manga Val., Costus speciosus (J. Koenig) Sm., Curcuma zedoaria Rox., Curcuma xanthorrhiza Roxb. orth. var. (Javanese turmeric), Curcuma hyneana Val. \& V. Zyp., Curcuma soloensis Val., Curcuma wenyujin H.Chen \& C.Ling, Curcuma oligantha Trimen, Curcuma aeruginosa Roxb., Curcuma phaeocaulis Val., Curcuma aromatica Roxb. (wild turmeric), Etlingera elatior (Jack) R.M. Sm., Zingiber cassumunar Roxb., Zingiber zerumbet L. (6-9). Several pharmacological activities have been ascribed to curcumin as a pure compound, such as antioxidant, antimicrobial and anti-inflammatory properties (10-12). The recent literature has shown curcumin as one of the most interesting pleiotropic nutraceuticals capable of interacting with different molecular targets involved in inflammation and oxidative stress. Moreover, curcumin showed positive effects as vasculo- and neuro-protective agent (13-15), and beneficial properties in skin diseases (16).

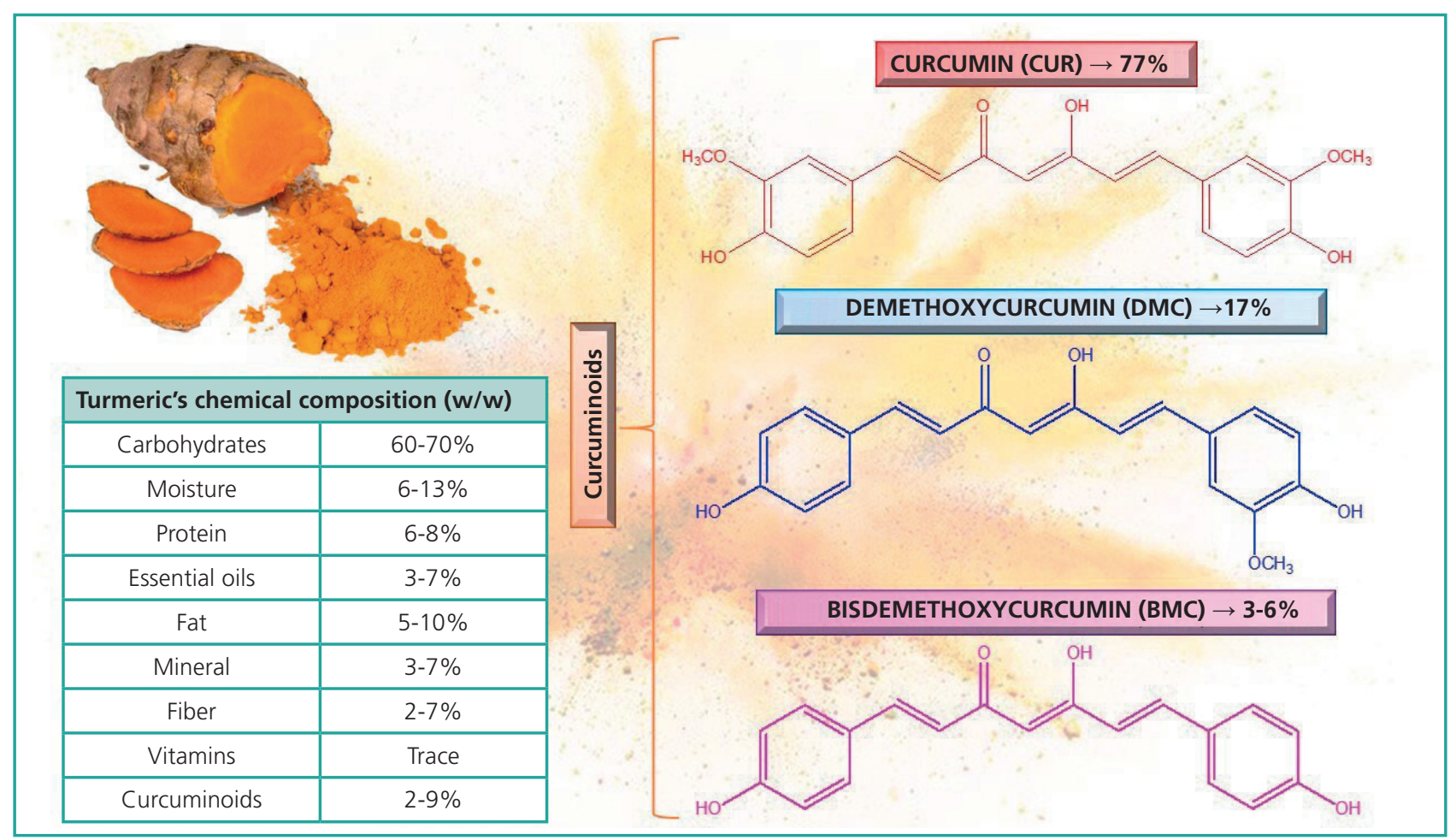

Figure 1. Representation of the major constituents of Curcuma longa L.

Curcumin (CUR), demetoxycurcumin (DMC), and bisdemethoxycurcumin (BMC) are generally grouped together under the name curcuminoid, which represents 2-9\% of turmeric by weight. Among the curcuminoids, CUR, DMC, and BMC account approximately for $77 \%, 17 \%$, and 3-6\%, respectively. 
The present review summarizes the very recent literature published between 2018 and 2021. We reviewed only the preclinical pharmacological actions for which extensive clinical investigation has been reported, mostly based on systematic review and meta-analyses of clinical trials (17). Curcumin chemistry, pharmacokinetic in humans and mode of action are also reviewed. The discussion of clinical data on its efficacy as well as the new pharmaceutical formulations developed to improve its oral absorption are outside the scope of this article.

\section{CHEMISTRY}

Thanks to its numerous health effects, curcumin has been extensively investigated from a chemical point of view. The IUPAC name of curcumin is $(1 E, 6 E)-1,7-b i s(4-h y d r o x y-3-m e-$ thoxy phenyl)-1,6-heptadiene-3,5-dione, its chemical formula is $\mathrm{C}_{21} \mathrm{H}_{20} \mathrm{O}_{6}$ and it possesses a molecular mass of $368.38 \mathrm{~g} / \mathrm{mol}$. Curcumin is a symmetric compound whose structure comprises three chemical units consisting of 2 aromatic ring systems containing O-methoxy phenolic groups linked through an $\alpha, \beta$-unsaturated $\beta$-diketone moiety (figure 2$)(18,19)$.
This structure led to an extended conjugation due to the electron cloud spanning along the molecule. For this reason, in the solution, curcumin can exist in cis-trans isomers where the trans-form is slightly more stable than the cisform for the presence of the 2 phenolic-methoxy groups in the opposite sides of curcumin backbone (20). Furthermore, the diketone moiety, for the intramolecular hydrogen atom transfection, is subjected to keto-enol tautomerism, and this tautomeric form can even exist in several cis-trans forms. Thus, depending on different factors like polarity of the solvent, temperature, and substitution on the aromatic rings, curcumin can exist in different types of conformers (19). In particular, when curcumin is in the crystal state, it appears in a cis-enol configuration stabilized by resonance; in this case, the structure consists of 3 planar groups interconnected by 2 double bonds (20). Generally, the keto-enol tautomerism of curcumin depends on the solution's pH: the enol-form dominates under alkaline conditions while the keto-form under neutral and/or acidic conditions (21) (figure 3). This presence of the enol form into the alkaline condition can be rationalized by forming the intramolecular hydro-

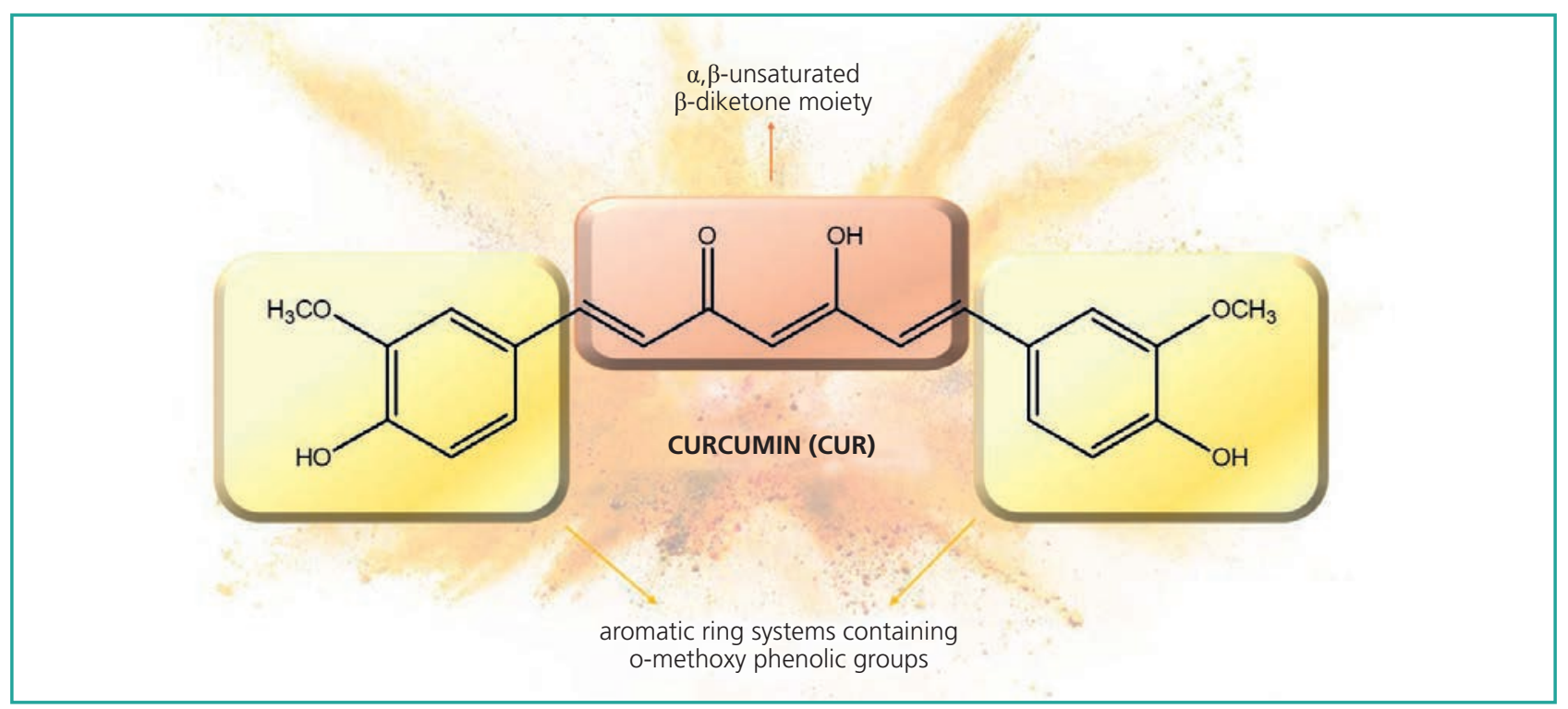

Figure 2. Representation of curcumin chemical structure. The symmetric structure of curcumin comprises three chemical units consisting of 2 aromatic ring systems containing O-methoxy phenolic groups linked through an $\alpha, \beta$-unsaturated $\beta$-diketone moiety. 


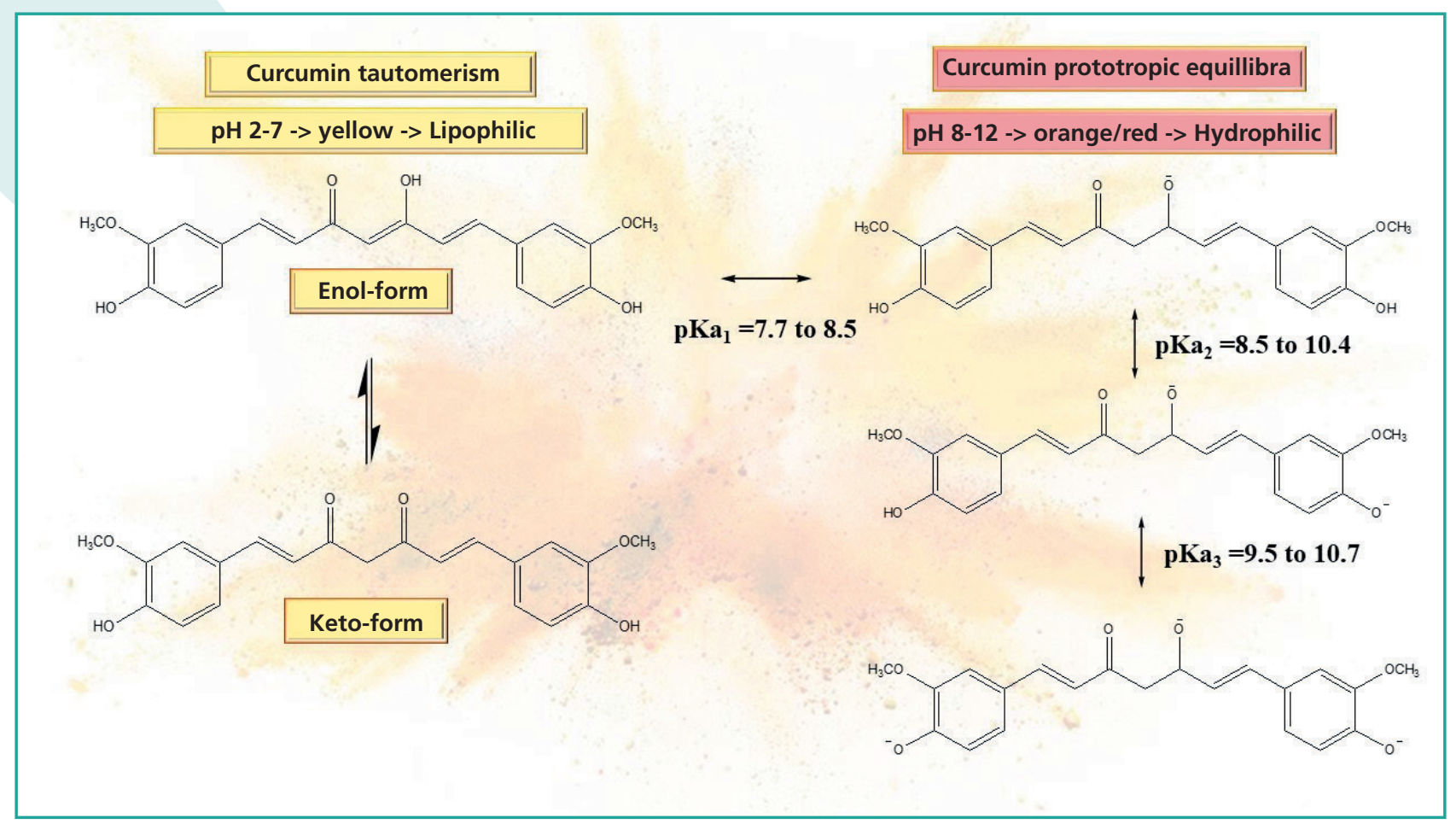

Figure 3. Representation of curcumin tautomerism and prototropic equilibria. The keto-enol tautomerism of curcumin depends on the solution's pH: the enol-form dominates under alkaline conditions while the keto-form under neutral and/or acidic conditions.

gen bond, which is generated when curcumin exists in the enolic form (1).

Curcumin is insoluble in aqueous solution at either neutral or acidic $\mathrm{pH}$; however, for its lipophilic nature $(\log P 3.0)$ it is soluble in organic solvents like ethanol, methanol, dimethyl sulfoxide, and acetone. The solubility of curcumin in an aqueous solution rises under alkaline conditions, although it should be considered that curcumin rapidly degrades under both alkaline and neutral condition (1).

The enol-form of curcumin possesses three ionizable protons represented by the enolic group and two phenolic groups (4). Thus, in this form, curcumin is a weak Brönsted acid with three prototropic equilibria at three different $\mathrm{pK}_{\mathrm{a}} \mathrm{s}$. The first $\mathrm{pK}_{\mathrm{a}}$ ( $\mathrm{pH}$ range of 7.5 to 8.5) changes the colour of curcumin from yellow to red. Furthermore, in the basic $\mathrm{pH}$ range, the anionic curcumin solubility in water is greater than the neutral form (20).

Regarding curcumin's biological activities, it was seen that they are related to the presence of
3 reactive sites: Michael acceptor, hydrogen atom donor, and metal chelator. In particular, the $\alpha, \beta$-unsaturated $\beta$-diketone moiety acts as a metal chelator and also as a Michael acceptor in a nucleophilic addition reaction. Furthermore, all 3 active curcumin sites (the 2 aromatic ring systems containing o-methoxy phenolic groups and an $\alpha, \beta$-unsaturated $\beta$-diketone moiety) can undergo oxidation by the transfection of electrons and the abstraction of hydrogen. All these pharmacophoric sites are strictly related to the anti-inflammatory, antioxidant, anticancer, and neurotrophic activity of curcumin. In the following section of the review, the main biological activities of curcumin will be analyzed.

\section{MOLECULAR TARGETS OF CURCUMIN}

Curcumin exerts pharmacological actions by interacting, directly or not, with a number of molecular targets, including transcription factors (2224), inflammatory mediators (25), protein kinases (26), and enzymes (27) (for review see (28)). 
Curcumin reduces nuclear factor kappa-B (NF$\kappa \mathrm{B})$ activation and its Nuclear translocation by inhibiting phosphorylation of p65 subunit and degradation of NF-kB inhibitor alpha $(\mid \kappa B \alpha)$ $(22,25,29-31)$. NF- $\mathrm{KB}$ is a transcription factor that regulates the genic expression of the main pro-inflammatory cytokines (e.g. interleukin (IL)-1, IL-2, and interferon- $\gamma$ (IFN $\gamma$ )) involved in pathways associated with inflammation, pain and tumorigenesis (32).

Curcumin is also a potent inhibitor of 5-lipoxygenase (LOX, that may contribute to its anti-inflammatory effect) (27), and activates the mitogen-activated protein kinases (MAPKs)/ Akt signaling pathways, which are mainly involved in mitosis, differentiation, cell proliferation, and cell survival/apoptosis $(33,34)$. Specifically, it has been reported that curcumin: (i) inhibits the IRS-1/AKT/PRAS40/Raptor/mTOR signaling cascade by inducing the proteasomal degradation of IRS-1 in colorectal cancer cells (35); (ii) reduces human aortic valve interstitial cells differentiation by suppressing the phosphorylation of extracellular signal-regulated kinases (ERK), $1 \kappa B \alpha$ and Akt (26); (iii) increases the nuclear factor-E2-related factor (NRF2) through an increase of the brain-derived neurotropic factor (BDNF) and ERK1/2 activation (36); (iv) increases PTEN expression and consequently decreases (via a selective packaging of miR-21 in exosomes) Akt phosphorylation, resulting in leukemic cell growth (37).

Also, curcumin protects against the development of neuropathic pain mainly through its inhibitory action on NF- $\mathrm{B}$, ERK and c-Jun $\mathrm{N}$-terminal kinase (JNK) in pain models associated with peripheral nerve injury (38).

More recently, curcumin has been shown to reduce the proliferation of melanoma cells through the downregulation of $\mathrm{Wnt} / \beta$-caten-

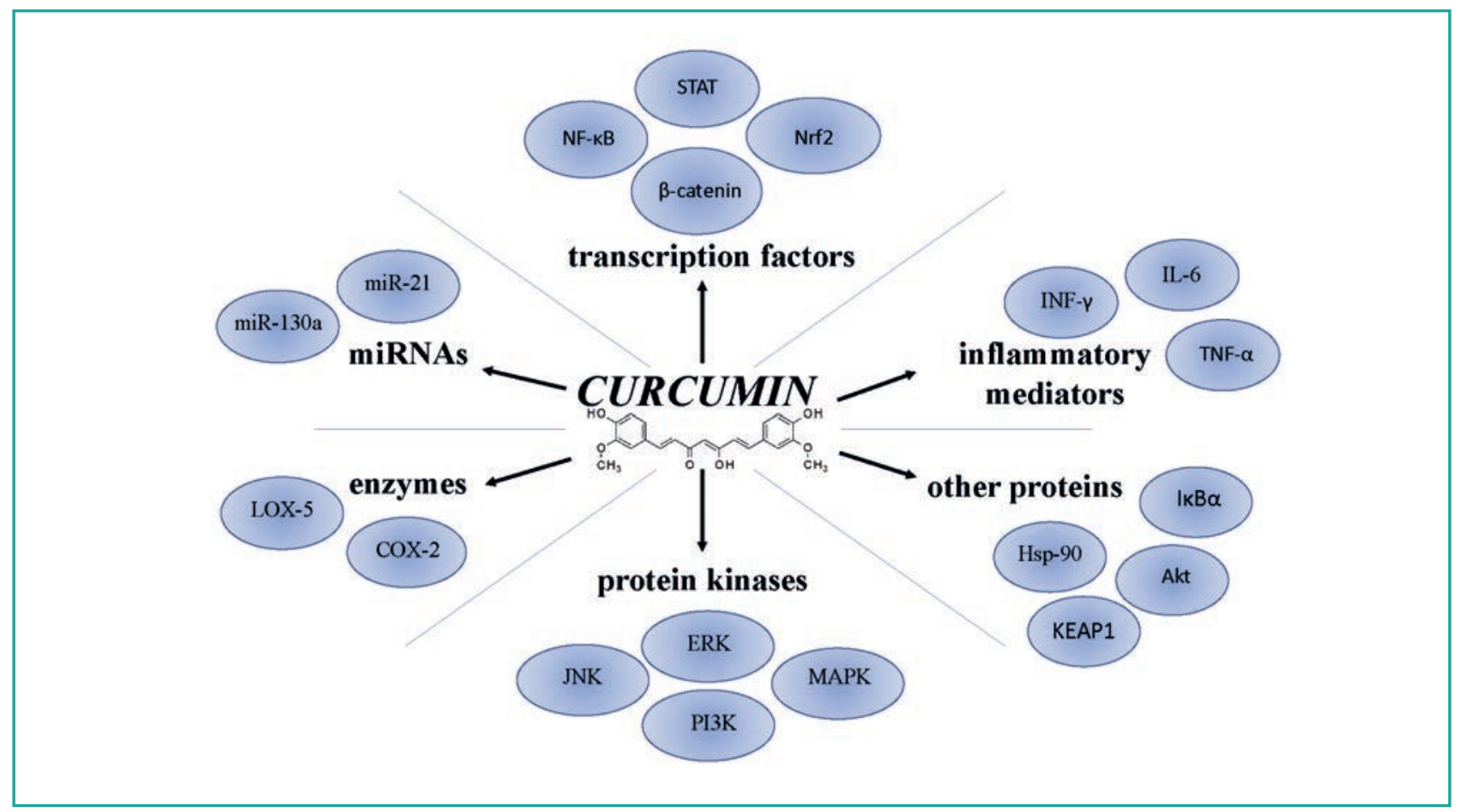

Figure 4. Schematic representation of the main molecular targets of curcumin.

The pharmacological effects of curcumin might be explained by the interactions with several targets which include transcription factors, pro-inflammatory mediators, enzymes, and protein kinases.

5-lipoxygenase (LOX); c-Jun N-terminal kinase (JNK); cyclooxygenase-2 (COX-2); extracellular signal-regulated kinases (ERK); heat shock protein 90 (Hsp90); interferon- $\gamma$ (IFN $\gamma$ ); interleukin (IL)-1, IL-2; Kelch-like ECHassociated protein 1 (KEAP1); miR-130a; miR-21; mitogen-activated protein kinases (MAPKs); NF- $\kappa B$ inhibitor

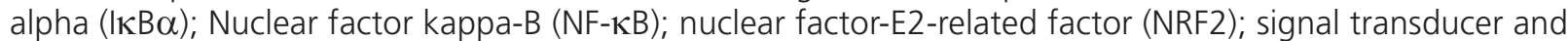
activation transcription (STAT); $\beta$-catenin. 
in signaling pathway proteins DVL2, $\beta$-catenin, cyclin D1, COX-2, and Axin2 (24). Also, curcumin suppresses the $\mathrm{Wnt} / \beta$-catenin pathway via miR-130a (an inhibitor of the negative regulator Nkd2) in colon cancer cells SW480 (39). Additionally, curcumin has been reported as a modulator of the signal transducer and activation transcription (STAT) proteins. Specifically, curcumin inhibits i) IL-6-induced STAT3 phosphorylation and its consequent nuclear translocation and ii) IFN- $\gamma$-induced STAT1 phosphorylation. Both nuclear factors are involved in promoting inflammation, cells proliferation and angiogenesis $(30,31,40,41)$.

Finally, the antioxidant effect of curcumin is mainly correlated to KEAP1-NRF2-ARE pathway $(42,43)$. Curcumin induces NRF2 upregulation, mainly by binding to Kelch-like $\mathrm{ECH}$-associated protein 1 (KEAP1), resulting in oxidative stress reduction $(31,44,45)$. Nonetheless, it has been reported that curcumin exerts a neuroprotective effect by reverting the increased expression of heat shock protein 90 (Hsp90) in models of neurotoxicity (46).

In summary, the diverse and various pharmacological effects of curcumin might be explained by the interactions with several targets, the most relevant of which include transcription factors, pro-inflammatory mediators, enzymes, and protein kinase (figure 4).

\section{PHARMACOKINETIC OF CURCUMIN IN HUMANS}

Curcumin is poorly absorbed after oral administration, due to a very low water solubility, to the spontaneous degradation (particularly at ph > 7) into ferulic acid, feruloylmethane, vanillin, hexenal and bicyclopentadione derivatives; it is also metabolized in the intestinal mucosa and liver, and by enzymes produced by the intestinal microbiota $(47,48)$. Data from studies on rats and mice indicate that the oral bioavailability of curcumin is as low as approximately $1 \%$ and most of the orally administered curcumin is eliminated in the feces (47). The portion of curcumin that is not eliminat- ed through the fecal route is extensively metabolized. Curcumin is subjected to both conjugation reactions that give rise to curcumin glucuronide and curcumin sulfate, and to reduction reactions that give rise mainly to tetrahydro-curcumin and hexahydro-curcumin and to a lesser extent to dihydro-curcumin and octahydro-curcumin (also named hexahydrocurcuminol), which are then conjugated with glucuronic acid and sulfuric acid (47). Intestinal and hepatic alcohol dehydrogenases and a NAPDH-dependent curcumin/dihydrocurcumin reductase produced by strains of Escherichia coli contribute to the synthesis of the reduced metabolites of curcumin $(48,49)$.

Several papers are available in the literature reporting data from pharmacokinetic studies on curcumin in humans. In some of them, however, the plasma samples were subjected to pre-treatment with $\beta$-glucuronidase, with or without sulfatase, before the quantification of curcumin concentrations, so that they do not really study the pharmacokinetics of curcumin. Consequently, these studies were not considered. In addition, we have focused on the studies conducted using rhizome extracts of Curcuma longa L., most of which have used the product called "Curcumin C3 Complex" or "C3 Complex" or "C3" produced by Sabinsa Corporation (East Windsor, NJ, USA).

To date, no studies have investigated the pharmacokinetic parameters (oral bioavailability, distribution volume and systemic clearance) of curcumin, demethoxy-curcumin and bisdemethoxy-curcumin, the other two main curcuminoids contained in the rhizome extracts of Curcuma longa L., in humans. In most clinical studies, the plasma concentrations of curcumin were measured at various times after administration of products containing curcuminoids. These studies only allow an estimate of the oral absorption of these molecules.

Sharma et al. (2001) administered 2 to 10 capsules per day of the product P54FP, each of which contains $18 \mathrm{mg}$ of curcumin and $4 \mathrm{mg}$ of demethoxy-curcumin in $200 \mathrm{mg}$ of essential oil obtained from Curcuma spp., correspond- 
ing to curcumin doses of $36-180 \mathrm{mg}$, to 15 patients with intractable colorectal adenocarcinoma (50). In this study, no quantifiable levels of curcumin or its metabolites in either plasma or urine were detected. However, in these patients' feces, important levels of curcumin were found, up to about $388 \mu \mathrm{g} / \mathrm{g}$ of dried feces in patients who had taken the highest dose of the product.

Sharma et al. (2004) administered higher single daily doses of curcuminoids (500 mg-4 g) as the "C3" product, each capsule of which contained $450 \mathrm{mg}$ of curcumin, $40 \mathrm{mg}$ of demethoxy-curcumin and $10 \mathrm{mg}$ of bisdemethoxy-curcumin, to patients with colorectal cancer no longer treatable with conventional therapies, until disease progression or withdrawal of consent (up to four months) (51). Curcumin was detected in plasma in only 3 of 6 patients treated with $4 \mathrm{~g}$ of curcuminoids, at mean levels of $11.1 \mathrm{nM}$ half an hour or one hour after administration on days 1, 2, 8 and 29. Curcumin sulfate and curcumin glucuronide were detected in the plasma of all 6 patients taking this dose, at mean levels of 8.9 $\mathrm{nM}$ and $15.8 \mathrm{nM}$, respectively. Authors found both curcumin and its conjugated metabolites in the urine and high levels of curcumin in the stools of these 6 patients, up to about $43 \mu \mathrm{g} / \mathrm{g}$ of dried stool.

Garcea et al. (2004) found very low levels of curcumin, curcumin glucuronide, and curcumin sulfate, close to the limit of detection ( $3 \mathrm{nM})$ of the assay method, in the portal blood collected during surgery from 4 patients with liver metastases from colorectal adenocarcinoma, seven hours after taking a dose of $4 \mathrm{~g}$ of curcuminoids (52). They administered to patients the "Curcumin C3 Complex" product, which contained $450 \mathrm{mg}$ of curcumin, $30 \mathrm{mg}$ of demethoxy-curcumin and $20 \mathrm{mg}$ of bisdemethoxy-curcumin in each $500 \mathrm{mg}$ capsule. Patients had taken this dose every day for the 7 days before surgery. At levels not reported in the paper, curcumin was also found in the systemic circulation of two of these patients one hour after taking the dose. Curcumin and conjugated metabolites were not detected in either the portal or peripheral blood of patients treated with doses of $500 \mathrm{mg}$ and $2 \mathrm{~g}$. The same group published a year later a study again conducted on patients with colorectal cancer, with the same product ("Curcumin C3 Complex"), at the same doses (0.5-4 g), and for the same period of administration (7 days; (53)). Curcumin was detectable at levels above the limit of detection of the assay method $(0.3 \mathrm{nM})$, but below the limit of quantification ( $3 \mathrm{nM})$, in the systemic circulation of only one patient, one hour after taking the dose of $4 \mathrm{~g}$. No metabolites of curcumin were detectable in plasma.

Similar results were obtained in a study conducted on 24 healthy volunteers receiving doses of curcuminoids in the range $500 \mathrm{mg}-12 \mathrm{~g}$ as the "C3 Complex" product containing a minimum 95\% of curcumin, demethoxy-curcumin and bisdemethoxy-curcumin (54). Measurable plasma concentrations were observed in only two subjects taking $10 \mathrm{~g}$ or $12 \mathrm{~g}$ of the product, with $C_{\max }$ of $50.5 \mathrm{ng} / \mathrm{mL}$ at 4 hours and $57.6 \mathrm{ng} / \mathrm{mL}$ at 2 hours, respectively. The same group then published a work conducted on 12 healthy volunteers divided into two treatment groups, who received the product "C3 Complex" at doses of $10 \mathrm{~g}$ and $12 \mathrm{~g}$ of curcuminoids, respectively. Each 250 mg capsule of "C3 Complex" contained $187 \mathrm{mg}$ of curcumin, $58 \mathrm{mg}$ of demethoxy-curcumin and $5 \mathrm{mg}$ of bisdemethoxy-curcumin (55). Measurable plasma concentrations of curcumin were observed in only one subject, half an hour after taking the $10 \mathrm{~g}$ dose. Pretreatment of plasma with glucuronidase and sulfatase allowed, on the other hand, detecting $\mathrm{C}_{\max }$ of curcumin around values of 0.9-2 $\mu \mathrm{M}$. Similarly, in two other studies in which $4 \mathrm{~g}(56)$ or 12 $g$ (57) doses of curcuminoids were administered to 12 and 10 healthy volunteers, respectively, no curcumin was detected in plasma in any of the enrolled subjects (limit of quantification of the assay method: $2 \mathrm{ng} / \mathrm{mL}$ and $1 \mathrm{ng} / \mathrm{mL}$, respectively). Also in these studies, the "Curcumin C3 Complex" product was used.

Pharmacokinetic studies with the product "Curcumin C3 Complex" have also been con- 
ducted in patients with Alzheimer's disease (58). This product, at doses of $2 \mathrm{~g} /$ day and $4 \mathrm{~g} /$ day, and a placebo were administered in parallel to 36 patients (12 patients per arm) for 24 weeks. At the visit programmed at week 24 , patients underwent blood sampling before taking the $4 \mathrm{~g}$ dose and at various times after taking the dose. The levels of curcumin and tetrahydro-curcumin were measured by liquid chromatography/tandem mass spectrometry in the plasma before taking the dose and 3 hours after taking the dose. Mean baseline levels of curcumin and tetrahydro-curcumin were approximately $2.7 \mathrm{ng} / \mathrm{mL}$ and $6.9 \mathrm{ng} / \mathrm{mL}$, respectively. Three hours after taking the dose, the levels of these two molecules were approximately $7.8 \mathrm{ng} / \mathrm{mL}$ and $3.7 \mathrm{ng} / \mathrm{mL}$, respectively. Pretreatment of the plasma samples with $\beta$-glucuronidase allowed to detect much higher levels of the glucuronidated metabolites of these two substances, ranging between about 96 and $298 \mathrm{ng} / \mathrm{mL}$ (58).

In conclusion, the analysis of the available literature allows only to state that the oral absorption of curcumin, administered by rhizome extracts of Curcuma longa L., is very low, with plasma levels that are in the low nanomolar range after taking doses of the extract of 4-12 g. No information is yet available on pharmacokinetic parameters of curcumin in humans.

\section{INFLAMMATION AND PAIN}

There is some evidence that curcumin-containing supplements may exert anti-inflammatory and analgesic actions in patients with arthritis-related diseases and inflammatory bowel disease (59). Detailed experimental information on the analgesic, antiarthritic and gut anti-inflammatory effects of curcumin, is reported below.

\section{Antiarthritic actions}

Arthritis derives from the Greek language and is composed of arthro-, meaning "joint" and -itis, meaning "inflammation". Arthritis represents a group of pathologies principally characterized by articular and structural damage, inflammation and pain (60). More than one hundred different types of arthritis have been described: the most prevalent forms are osteoarthritis (OA), rheumatoid arthritis (RA), spondyloarthritis (SpA), psoriatic arthritis (PsA), crystal-induced arthritis, and related autoimmune diseases. Although these diseases arise from different causes, they exhibit similar symptoms and treatments (61). Current drug therapy for arthritis includes analgesics, disease-modifying antirheumatic drugs (DMARDs) in combination with corticoids, and non- steroidal anti-inflammatory drugs (NSAIDs) to reduce both severe pain and inflammation (62). Despite NSAIDs represent conventional first-line treatment, they are associated with gastrointestinal and cardiovascular adverse events, mainly due to long-term use and high dosages (63). Therefore, plant-derived products with anti-inflammatory properties and minimal side effects are gaining interest in the treatment of arthritis (64). Multiple studies proved curcumin therapeutic effects against several inflammatory, neuronal, cardiovascular, gastrointestinal, endocrine, and metabolic diseases, including diabetes, arthritis, obesity, and cancer (65). It is well known that curcumin acts on different signaling pathways, in particular inhibiting the production and activity of nuclear factor kappa-B (NF-kB), toll-like receptor 4 (TRL4), mitogen-activated protein kinase pathways (MAPKs), cyclooxygenase-2 (COX-2) and inflammation-associated markers including the main cytokines involved in the inflammatory cascade of arthritis, such as interleukin (IL)-1 $\beta$, IL-6, IL-8, and tumor necrosis factor-alpha (TNF- $\alpha$ ) (66-69).

Several groups proved curcumin therapeutic effect against the progression of arthritis. Two recent studies showed the in vitro and in vivo efficacy of curcumin in monosodium urate (MSU)-induced gouty arthritis. Li et al. (2019) observed that curcumin exerted a significant reduction in MSU-induced NLR family pyrin domain containing 3 (NLRP3) inflammasome expression, possibly through inhibition of 
the TLR4/NF- $\mathrm{kB}$ signaling pathway in macrophages (70). These results were supported by an in vivo experiment showing that curcumin, $200 \mathrm{mg} / \mathrm{kg}$, could protect rats from MSU-induced gouty arthritis. In line with the previous study, Chen et al. (2019) found that curcumin treatment improved MUS-induced inflammation by suppressing $\mathrm{IkB} \alpha$ degradation, NF-kB signaling and NLRP3 inflammasome activation (71). Another research explored the protective effect of curcumin on monosodium iodoacetate (MIA)-induced knee osteoarthritis (OA). Intravenous injection with curcumin (200 mg/ $\mathrm{kg}$ ) inhibits TLR4/NF- $\mathrm{kB}$ signaling pathway and reduces inflammation, improving knee function in an OA rat model (72). Curcumin also showed therapeutic effects on rat anterior cruciate ligament transection (ACLT) osteoarthritis, by interfering with oxidative stress, which plays a crucial role in the development of OA through activation of endoplasmic reticulum (ER) stress and chondrocyte apoptosis. Curcumin significantly attenuated ER stress both in vitro and in vivo, by suppressing the Protein Kinase R-like ER Kinase (PERK)-phosphorylation of eukaryotic initiation factor-2alpha (elF2 $\alpha$ )-activating transcription factor 4 (ATF4)-C/EBP homologous protein (CHOP) signaling pathway and reducing $\mathrm{CHOP}$ expression, a biomarker of ER stress and apoptotic activation in chondrocytes (73). Furthermore, curcumin increased the expression of silent information regulator factor 2-related enzyme 1 (SIRT1) in a dose-dependent manner, and in previous studies SIRT-1 has been shown to play a key role in the regulation of ER stress-related chondrocyte apoptosis (74). These findings could suggest the activation of SIRT-1 and inhibition of ER stress as potential mechanisms underlying effects of curcumin in ACLT rat OA model (73). Moreover, curcumin has been shown to relieve inflammation, synovial hyperplasia and other symptoms in a rat rheumatoid arthritis model by suppressing Akt/mammalian target of rapamycin (mTOR) pathway and decreasing IL-1 $\beta$, TNF- $\alpha$, matrix metalloproteinases (MMP)-1, and MMP-3 lev- els (75). A further study investigated the possible correlations between cartilage protection exerted by curcumin in OA and autophagy promotion. Curcumin decreased apoptosis and enhanced autophagy, playing a protective role on cartilage degradation and chondrocyte apoptosis, in both age-related and surgically induced mice OA, through inhibition of Akt/ mTOR signaling pathway, as indicated by increased autophagy key regulators light chain 3 (LC3) and Beclin 1. These results were supported by a study involving an OA cell model that validated curcumin efficacy by modulating inflammatory cytokines and autophagy inhibitors; curcumin treatment improved autophagy reduction, cell viability decrease, and apoptosis (76). Recently, Chen et al. (2020) confirmed the protective effects of curcumin on IL-1 $\beta$-induced chondrocyte apoptosis through activating autophagy and inhibiting NF-KB pathway (77). Overall, increasing in vitro and in vivo evidence suggests that curcumin could be a promising treatment for different types of arthritis through its potent anti-inflammatory effects. Promising pre-clinical and pilot clinical trial data showed beneficial and safe results of curcumin in knee OA, as compared to conventional drug treatment, with similar benefits and a reduction of adverse effects (78-80). In conclusion, further studies are required to fully investigate the efficacy and bioavailability of curcumin as a long-term arthritis therapy.

\section{Inflammatory bowel disease}

Inflammatory bowel diseases (IBD) represent a set of immune-mediated gastro-intestinal disorders mainly represented by ulcerative colitis (UC) and Chron's disease (CD) (59). The etiology of IBD is still unknown, but it is believed to involve the overstimulation and the excessive response of the intestinal mucosal immune system to resident luminal microorganisms. According to the recent epidemiological studies, countries such as the United States, the United Kingdom, and the Northern Europe have a higher incidence rate of IBD comparing to the developing countries. However, recent- 
ly, it has been recorded in an increase of incidence and prevalence of IBD also in developing countries with a higher frequency for UC with respect to the CD (81). There are many pharmacological approaches available to treat IBD (cyclosporine, corticosteroids, 5-aminosalicylic acid, mercaptopurines, anti-TNF- $\alpha$, and azathioprine). Despite this, many of them have prohibitive costs and can cause serious adverse effects, as well as manifesting a limited effectiveness and specificity (82).

Considering this, researchers are increasingly interested in natural bioactive compounds, which possess strong anti-inflammatory and antioxidant activities, as new promising strategies to treat the IBD (81). The most investigated bioactive compound from this point of view is curcumin.

Different preclinical studies carried out on rodents have highlighted how curcumin shows anti-apoptotic, antioxidant, and anti-inflammatory properties (81) modulating many transcription factors such as NF-KB, $\beta$-catenin, activator protein 1, peroxisome proliferator-activated receptory (PPARy), different signal transduction pathways such as the p38-mitogen-activated protein kinase as well as by inhibiting enzymes involved in the onset of inflammation such as COX-2 and the inducible isoform of NO synthase (iNOS). Moreover, the down-regulation of pro-inflammatory cytokines such as interferon (IFN)- $\gamma$, TNF- $\alpha$, interleukin (IL)-1 $\beta$, IL-12 IL-15, IL-17, and IL-23, and the up-regulation of IL-4 and IL-10 have been observed in histological samples following administration of curcumin to murine models with induced colitis (83).

In inflamed intestine, curcumin can interact with transient potential vanilloid receptor 1 (TRPV1) improving the visceral hyperalgesia and colitis in mice (81). These results corroborate previous observations, which showed the curcumin ability to suppress the membrane TRPV1 upregulation induced by phorbol myristate acetate in the HEK293 cell line (81). Moreover, curcumin has a strong suppressive role in NLRP3 inflammasome activation in mice, down-regulating the dextran sulfate so- dium (DSS)-induced $\mathrm{K}^{+}$efflux, intracellular ROS formation and cathepsin $B$ release (81).

Beyond the clear inflammatory event, recently it has been shown that mutation in autophagy-related genes is associated with development of IBD and, also in this case, curcumin can play a pivotal role. Indeed, it has been demonstrated that its administration remarkably reduces the expression of autophagy target genes such as Beclin-1, autophagy-related gene 5 (ATG5) and LC3II, leading to improvement in colitis (81). Furthermore, curcumin was able to reduce autophagosome formation in intestinal epithelial cells in a mouse model of DSS-induced colitis (81).

IBD can lead to the onset of concomitant diseases such as a recurrent anaemia due to a poor iron absorption. Curcumin is able to modulate iron metabolism proteins, reducing the iron stores and restoring its physiological hematic level (81). Despite the description of clinical studies are beyond the scope of the present review, it should be noted that, to date, few clinical studies have been conducted to evaluate the clinical efficacy of curcumin $(59,84)$.

One of the main problems in evaluating the clinical efficacy of curcumin is that commercial formulations are often an impure blend consisting of $\sim 75 \%$ curcumin, $17 \%$ demethoxy curcumin, $3 \%$ bisdemethoxycurcumin and $5 \%$ $0 \%$ cyclocurcumin. Another limitation to the clinical application of curcumin as a therapeutic agent is its weak bioavailability, mainly due to its poor solubility in water $(\sim 11 \mathrm{ng} / \mathrm{mL})$, followed by a rapid metabolism and excretion (85). Moreover, curcumin is unstable in both basic and neutral environment. For this purpose, various strategies have been adopted to improve the pharmacokinetics of this molecule such as nanotechnologies. Considering this, further controlled and randomized clinical trials are needed to better define the role of curcumin in the treatment of IBD.

\section{Analgesic effects}

Pain and inflammation are the main pathological conditions underlying the chronic use of 
analgesic treatments. Despite many effective analgesic drugs belonging to different classes, including non-steroidal, opioid, non-opioid and others, their use is often limited by severe multi-organ adverse effects, and addiction. Therefore, the search for effective and safer alternative therapeutic options is an actual matter of debate. There is a growing interest in alternative medications, including herbal extracts that have long been used by folk populations in the conventional forms of infusions and decoctions. These traditional remedies could not only be effective and safe, towards chronic conditions such as pain, but also represent, in some cases, innovative strategies for implementing local botanical chain productions. In this regard, it is sensitive to highlight the potential use of Curcuma species extracts and natural compounds for treating pain. Turmeric (Curcuma longa) has a long traditional use in the Ayurvedic medicine for counteracting musculoskeletal pain (86). In the last decade, multiple studies were conducted on both Curcuma extracts and the main curcuminoid curcumin; in natural formulas it is also possible to find turmeric extracts mostly con- stituted by curcumin $(87,88)$. In preclinical experimental paradigms of nociception, namely tail-flick and acetic acid-induced writhing tests, the administration of curcumin 15-120 $\mathrm{mg} / \mathrm{kg}$ determined a dose-dependent pain relief effect (89). The antinociceptive efficacy of curcumin was compared to that of pregabalin. Specifically, curcumin was as potent as pregabalin, whereas the pharmacological association of the two compounds led to synergistic effects probably related to multiple concomitant mechanisms.

The efficacy of the sole curcumin as analgesic is consistent with the downregulation of different pro-inflammatory pathways $(17,90$, 91). Direct interactions of curcumin with target proteins involved in the inflammatory response are also predicted by the bioinformatics platform STITCH (http://stitch.embl.de/) (figure 5). In this regard, the results of the components-targets analysis confirmed a high probability (> 70\%) of peroxisome proliferator-activated receptor- $\gamma$ (PPAR $\gamma$, PPARG) activation and cyclooxygenase-2 (COX-2, PGTS2) inhibition induced by curcumin, as well. Recently, the efficacy of propofol in counteract-

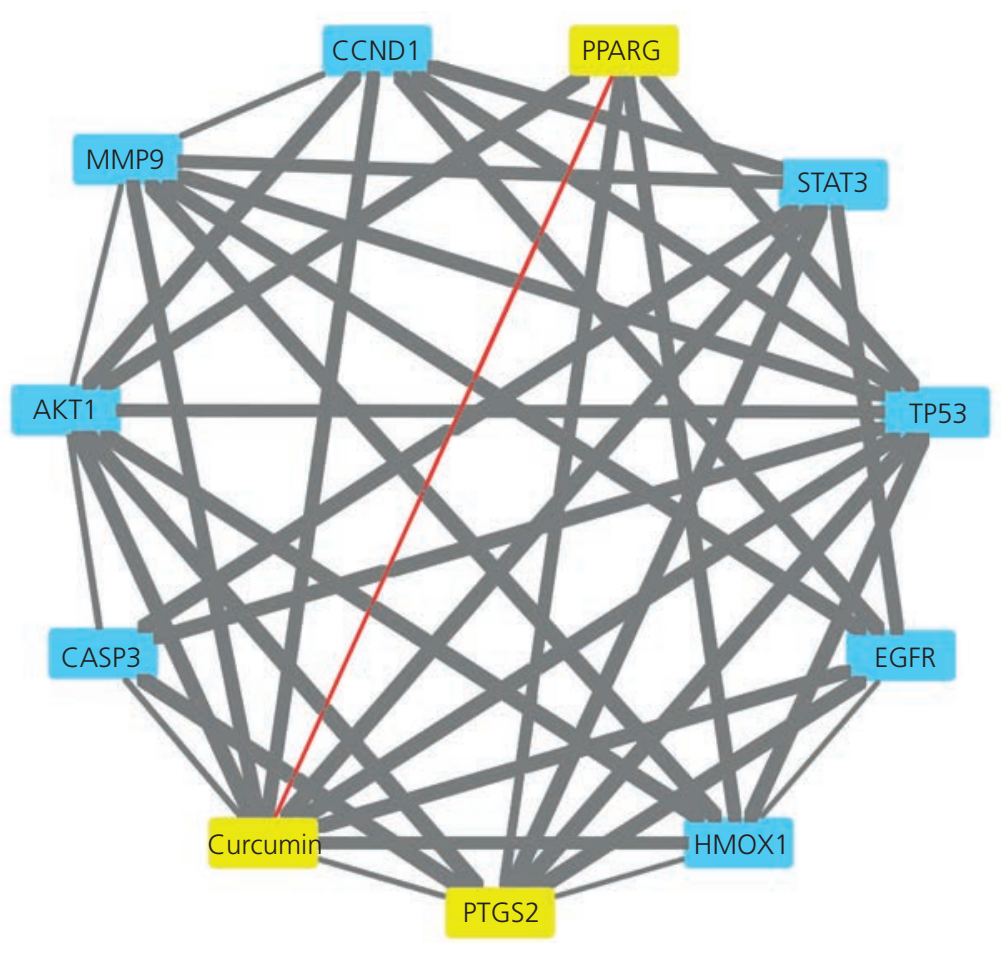

Figure 5. Components-targets analysis conducted on the bioinformatics platform STITCH (http://stitch.embl. de/) underlying putative interactions of curcumin with receptors and enzymes involved in the inflammatory response. Of noteworthy interest for the analgesic properties demonstrated by curcumin are the putative interactions with type cyclooxygenase-2 (COX-2, PGTS2) and peroxisome proliferator-activated receptor- $\gamma$ (PPAR $\gamma$, PPARG). 
ing the neuropathic pain has been related to the PPARy stimulation, as well (92).

The mechanism of action of curcumin as analgesic was also investigated in a new trigeminal neuralgia rat model induced by the injection of the cobra venom in the infraorbital nerve (93). The intra-gastric administration of curcumin was able to revert the cobra venom-induced mechanical allodynia, and this effect was also mirrored by the reduction of pain-induced depression, in rats. The same authors showed alterations on ether lipid and glycerophospholipid metabolism, as well. These findings also add to modulatory effects induced by curcumin on the activity of neurotransmitters and neuropeptides, such as monoamines and neurotrophic factors, regulating the neurogenesis and hypothalamic-pituitary axis, and possibly mediating the tight relationships occurring between depression and chronic pain (94-99). Recently, multiple studies also demonstrated the analgesic effect of curcumin in neuropathic pain. In the mouse chronic constriction injury model, an experimental paradigm mimicking neuropathic pain, curcumin exerted an analgesic effect that was related, albeit partially, to the inhibition of pro-inflammatory cytokines in both the sciatic nerve and the spinal cord (100). Similar results were also observed following the administration of nanocurcumin, whose efficacy in neuropathic pain was paralleled by decreased production of cytokines, in the rat hippocampus, with concomitant improvements of cognitive functions (101). The efficacy of curcumin towards neuropathic pain was demonstrated in streptozotocin-induced diabetic rats, as well. In this context, the analgesic effect was related to curcumin capability to induce the expression of the phosphorylated form of c-Jun N-terminal kinase (pJNK) located in the neurons and astrocytes of the dorsal root ganglion (DRG) (102).

The aforementioned preclinical results pointed to the efficacy of curcumin as analgesic, thus supporting the clinical use. However, concerns remain about the dosage regimen because of different factors, including the low bioavailability of curcumin and variability in the preparation of the formulations used in the studies $(103,104)$. Nevertheless, the oral administration of nanomicelle curcumin (40 mg twice a day) was effective in reducing pain in 36 patients suffering from knee osteoarthritis (105). The efficacy as analgesic was also observed when curcumin was topically administered (106). In this regard, a clinical trial demonstrated the efficacy of curcumin in patients suffering from recurrent minor apthous ulcers. The treatment was effective in reducing ulcer size, pain, healing, and recurrence, thus strongly supporting the clinical relevance of this natural compound. Collectively, pre-clinical and clinical findings seem to corroborate the analgesic efficacy of curcumin that is related, at least in part, to inhibitory effects on multiple pro-inflammatory pathways.

\section{METABOLIC EFFECTS}

\section{Effects on body weight and obesity}

Obesity is a rapidly increasing chronic disease due to a long-term imbalance between energy intake and energy expenditure (107). Obesity is considered a risk factor for developing a number of chronic diseases, such as cardiovascular diseases, type 2 diabetes mellitus, and some types of cancer (108). A growing body of evidence suggested that curcumin could exert beneficial properties on obesity and obesity-related metabolic diseases $(109,110)$. In this regard, curcumin has been reported to decrease body weight gain in both animals and human subjects (111-113). A study in mice showed that a very high-fat diet (VHFD) supplemented with curcumin $(0.7 \% \mathrm{w} / \mathrm{w})$ for 13 weeks led to a reduction in body weight gain and body fat, along with an increase in lean body mass (114). However, in disagreement with other studies (115), the same authors did not find any effect of curcumin on adipocyte cell size (114). On the other hand, other studies reported no effects of dietary curcumin on body weight and adiposity, in mice (116). 
Besides its modulatory effects on several molecular targets, such as NF-kB, IL-6, TNF- $\alpha$, IL-1 $\beta$, monocyte chemoattractant protein-1, and NLRP3 inflammasome (117), curcumin could also play a key role in adipogenesis. In this context, curcumin treatment inhibited the differentiation of murine 3T3-L1 preadipocyte cell line (118). Stimulation of white adipose tissue (WAT) lipolysis was also reported following daily curcumin $(50 \mathrm{mg} / \mathrm{kg})$ administration for 8 weeks, in high fat diet (HFD)-induced obese mice (113). Moreover, it has been observed that curcumin could significantly suppress adipogenic differentiation of human bone marrow mesenchymal stem cells, in a concentration-dependent manner, by decreasing mRNA and protein expression levels of Kruppel-like factor 15 (119). Promotion of brown adipose tissue (BAT)-mediated thermogenesis has been proposed as a possible therapeutic strategy against obesity (120). Recently, Song and collaborators (2018) reported that in HFD fed mice dietary curcumin supplementation increased energy expenditure and thermogenesis after cold exposure. Moreover, in vivo and ex vivo studies showed that curcumin decreased WAT inflammation and promoted uncoupling protein-1 (UCP-1) expression in BAT, possibly through PPAR $\alpha$ and PPAR $\gamma$-dependent and independent mechanisms (121). More recently, curcumin also enhanced the browning process as well as mitochondrial respiratory function in 3T3-L1 cells. These effects have been suggested to be related to stimulatory effects on PPAR $\gamma$, UCP-1, PR domain protein 16 (PRDM16), and PPAR $\gamma$ coactivator- $1 \alpha$ (PGC$1 \alpha$ ) expression levels (115).

Despite its beneficial properties on obesity, curcumin possesses low oral bioavailability related to low intestinal absorption and rapid elimination (122). Nishikawa and collaborators (2018) reported that, differently from native curcumin, oral administration of low dose highly dispersible and bioavailable curcumin formulation for 4 weeks was able to stimulate the formation of brown-like adipocytes in inguinal WAT and increase energy expenditure, in mice (123).
Further studies are necessary to better define the therapeutic potential of curcumin in the prevention and management of obesity.

\section{Effects on blood lipids}

Turmeric and curcuminoids, such as curcumin, demethoxycurcumin, and bisdemethoxycurcumin, have been described for their lipid-lowering effects in several preclinical and clinical studies (124-134). Curcumin is able to improve the metabolic status, decreasing serum triglycerides (TG) levels in streptozotocin (STZ)-induced diabetic mice $(124,125)$. Recently, Xia and collaborators (2020) also reported that pre-treatment with curcumin (300 $\mathrm{mg} / \mathrm{kg}$ body weight) for 12 weeks could prevent hyperglycaemia and hyperlipidaemia induced by high-fat diet combined with STZ treatment in rats, as well as liver damage, mainly through antioxidant and anti-apoptotic mechanisms. In particular, curcumin reduced fasting blood glucose (FBG), total cholesterol (TC), TG, low-density lipoprotein cholesterol (LDL-C), alanine aminotransferase (AST), and aspartate transaminase (ALT) levels (135). On the other hand, several studies have reported disappointing results on plasma HDL-C levels after curcumin treatment (136). The beneficial effects of curcumin on plasma lipid profile have also been compared with statins, a well-established treatment in hyperlipidaemia (137). Curcumin seems more effective in reducing TG, while statins in lowering LDL-C. On the other hand, despite curcumin was suggested in dyslipidemia treatment (138), recent works did not find any beneficial effects of curcumin on lipid and glucose profile, in mice fed a high-fat diet $(114,139)$. In particular, a high-fat diet supplemented with curcumin $(0,1 \%$ of curcumin and $0,01 \%$ pepper) for 4 weeks did not reduce serum levels of cholesterol, TG and glucose (139). Similarly, curcumin supplemented diet $(0.7 \% \mathrm{w} / \mathrm{w})$ did not modify serum TG levels in mice fed with a very high-fat diet for 13 weeks (114). The limitations of these studies could be related to dose of curcumin administered, duration of the study and method of supplemen- 
tation. The molecular mechanisms underlying the hypolipidemic effects of curcumin could involve oxidative and lipid-mediated stress in the vascular system (140). Curcumin could modulate the activity of specific transcription factors controlling the expression of genes involved in free radical scavenging and lipid homeostasis $(137,140,141)$. On the other hand, curcumin was found to decrease the expression of lipogenic enzymes and transcription factors, such as ATP-citrate lyase, Acetyl-CoA carboxylase and Fatty acid synthase in rats fed with a high-fructose diet (142). Different curcumin formulations with improved bioavailability have been studied for their effects on lipid metabolism (143, 144). A recent report examined the comparative effects of curcumin versus nano-curcumin on insulin resistance, serum levels of apelin and lipid profile in type 2 diabetic rats (145). Oral administration of curcumin and nano-curcumin (100 and $200 \mathrm{mg} /$ $\mathrm{kg}$ ) for 28 days improved serum lipid profile, in diabetic rats. In addition, the effects of nano-curcumin were more effective than curcumin, possibly due to increased solubility and bioavailability (145). Then it is desirable to improve the bioavailability of various curcumin formulations to examine its actual effects on lipid metabolism and HDL function $(143,144)$.

\section{Antidiabetic actions}

According to The World Health Organization, diabetes mellitus (DM) is going to be one of the leading causes of death worldwide (146), and type 2 diabetes mellitus (T2DM) represents the most prevalent form with a remarkable impact on public health. T2DM is mainly characterized by insulin resistance that leads to hyperglycemia and its relative long-term complications including macrovascular and microvascular damage, retinopathy, neuropathy, and nephropathy (147). The leading hypothesized mechanisms to explain insulin resistance and $\beta$-cells impairment have been oxidative stress, deregulation of lipid deposition in several organs which in turn lead to inflammatory responses (148). Since T2DM to date cannot be cured, the current approach is focused on the control of disease progression by the use of lifelong anti-diabetes drugs (149), although, limiting the number of T2DM new occurrences should be the key strategy to counteract its health impact. Due to the burgeoning healthcare costs and the pharmacological side effects that negatively impact on the compliance, the scientific community has shown a growing interest in new effective therapeutic agents from medicinal plants (150).

Accumulating evidence suggests that curcumin could be a promising agent against T2DM improving some key aspects related to T2DM pathogenesis such as $\beta$-cells function, insulin resistance and mitigating oxidative stress and inflammation (151). Results from streptozotocin (STZ)-induced diabetic rat models showed how curcumin supplementation at a dose ranging from 30 to $100 \mathrm{mg} / \mathrm{kg}$ b.w. per os effectively counteracts hyperglycemia improving insulin response (152), and there is compelling evidence that curcumin reduces oxidative stress and lipid peroxidation, inducing antioxidant enzyme activities as recently reviewed (147). Curcumin administered for 21 days as diet supplementation (1\% weight ratio) decreased circulating malondialdehyde (MDA) levels, while SOD and insulin levels were increased in a STZ-induced diabetic rat model (153). Benefits against renal dysfunction and oxidative stress were also raised from the study by Lima and colleagues (154) that showed how STZ-induced diabetic rats treated orally with curcumin ( $90 \mathrm{mg} / \mathrm{kg}$ b.w./day, for 45 days) showed lower glycaemia levels and a marked decrement of advanced glycation biomarkers and oxidative stress in the plasma, liver, and kidney (154). In the last decade, the antioxidant effects of curcumin were investigated indepth and promising results also come from alloxan-induced diabetes models where curcumin $(0.08 \mathrm{mg} / \mathrm{kg}$ b.w./day orally for 21 days) significantly decreased serum glucose and glycated hemoglobin concentration, as well as liver and serum MDA whereas glutathione level and GPx activity were increased (147). Con- 
sistently, data from genetic and diet-induced diabetes models (high-fat diet and high-sucrose diet) confirmed that curcumin orally administered at dosage of $90 \mathrm{mg} / \mathrm{kg}$ b.w. for 9 weeks ameliorated insulin resistance, glucose intolerance, inflammation, and it boosted the enzymatic antioxidant machinery (155).

Along with oxidative stress, inflammation also plays a key role in diabetes progression and its complications occurrence. Several studies indicated that curcumin administration ameliorates inflammatory response inhibiting the expression of NF- $\mathrm{KB}$ target genes such as IL-6, TNF- $\alpha$, MCP-1 as well as 8-hydroxy-2'- deoxyguanosine (8-oxo-dG) $(149,156)$.

These aspects are of great interest since TNF $\alpha$ and IL-6 are known to promote insulin resistance (157). Furthermore, curcumin counteracts the glucose-induced over-expression of TNF- $\alpha$ IL-1 $\beta$ and IL-6 (158). Intriguingly, the inhibition of IL-1 system by curcumin expression is of particular interest considering that it contributes to both $\beta$-cells impairment and apoptosis (159).

Obesity is a relevant causal factor in the etiology of insulin resistance (160). Adipose tissue contributes to chronic inflammation by activating protein kinases related and TNF- $\alpha$ receptors, such as the inhibitor of kappa B kinase (IKK) and JNK, which phosphorylates IRS-1 reducing its interaction with the insulin receptor leading to a decrease in insulin signaling transduction (161). The JNK signaling pathway seems to be one of the most important mechanisms connecting insulin resistance in obese patients (162), noteworthy, JNK knockout mice show lower adiposity, enhanced sensitivity to insulin and an increased capacity for insulin receptor signaling even under the lipid-rich regimen (160). Hence, the inhibiting effects of curcumin on this pathway achieve a considerable relevance (159).

Furthermore, curcumin diet supplementation reduces the gene expression of transcription factors involved in hepatic lipogenesis, such as the sterol regulatory element-binding protein 1c (SREBP1c), which promotes cholesterol synthesis and it can restore the expression of
PPARy, a key regulator of glucose/lipid metabolism in adipose tissue, skeletal muscle, heart, and liver which is down-regulated in diabetic mice (151); this could be a further beneficial effect of curcumin, in line with other drugs like thiazolidinediones that target the PPAR $\gamma$ expression.

Overall, promising results from both, preclinical and clinical studies, although the mechanisms by which curcumin exerts its effects are still not fully understood, suggest that curcumin can target key mediators of inflammation, improving $\beta$-cells function, antioxidant status and lipid metabolism, hence the interest of the scientific community for curcumin as a potential candidate against T2DM and its complications. Results from clinical trials seem to some extend confirm what emerged from in vivo studies; however, to date, further studies are mandatory to better draw the efficacy and the safety profile of curcumin and its specific dosage in T2DM patients (currently, FDA and EFSA maximum recommend 3 $\mathrm{mg} / \mathrm{kg} /$ day). Interestingly, although currently the medical practice guidelines do not recommend using curcumin during pregnancy, some investigations indicate a putative benefit effect on glycemic control in gestational diabetes mice $(163,164)$. This represents, beyond doubts, an intriguing aspect that deserves further investigations. The putative curcumin-drug interactions need to be better explored, as recently reviewed by Bahramsoltani et al.: some studies reported significant pharmacokinetic alterations such as changes in $\mathrm{C}_{\max }$ and $\mathrm{AUC}$ when co-administered with cardiovascular drugs, antidepressants, anticoagulants, antibiotics, and chemotherapeutic agents probably due to the inhibition of cytochrome P450 isoforms by curcumin (165). These should not surprise since it is known that numerous vegetables as well as their derivatives, especially when they are rich in polyphenols, can strongly affect the activity of xenobiotic metabolizing enzymes, therefore caution is mandatory in patients on polytherapy $(166,167)$. 
In conclusion, although further studies are needed, the encouraging results reassumed above makes curcumin as a prime candidate for clinical use against insulin resistance and T2DM.

\section{CARDIOVASCULAR EFFECTS}

The effects of curcumin against cardiovascular diseases have been indicated in several studies. Systematic reviews and meta-analyses of clinical trials have suggested that curcumin may improve endothelial function and blood pressure $(13,168)$.

\section{Blood pressure}

An increasing number of evidence shows that curcumin possesses cardioprotective efficacy in several animal models, and this effect seems mainly due to its vascular effects. In an in vivo animal model of $\mathrm{Pb}$ - and $\mathrm{Cd}$-induced hypertension accompanied by hemodynamic disturbances, orally administered curcumin $(100 \mathrm{mg} /$ $\mathrm{kg} /$ day for the last 4 week of the $\mathrm{Pb}$ - or $\mathrm{Cd}-16$ week exposure) significantly reduced by $50 \%$ the metal-induced increase in systolic blood pressure (SBP) induced by the metals (169). In addition, treatment with curcumin improved the hemodynamic status of metal exposed rats by lowering arterial blood pressure, decreasing heart rate (HR), and increasing hindlimb blood flow, thereby reducing peripheral vascular resistance. The effects of curcumin on HR may be related to the observed decrease in blood pressure with a subsequently restored baroreflex. Furthermore, $\mathrm{Pb}$ and $\mathrm{Cd}$ attenuated acetylcholine (Ach)-induced nitric oxide (NO)-dependent vasodilation and this effect was restored by curcumin (169). The amelioration in blood pressure values was then associated with the modulation of $\mathrm{NO}$ and endothelial nitric oxide synthase (eNOS), that were partially restored by curcumin. The effects on blood pressure were also confirmed also in a high-fat diet-fed rat model of hypertension since curcumin (orally administered at a dose of $100 \mathrm{mg} / \mathrm{kg} /$ day for the final eight weeks of the 16 weeks study) restored SBP to the controls (170).
In another in vivo experimental model of hypertension and kidney dysfunction induced by the eNOS antagonist L-NAME (L-N ${ }^{G}$-Nitro arginine methyl ester) in adult male Albino rats, curcumin (oral $100 \mathrm{mg} / \mathrm{kg} /$ day for 10 weeks) showed a significant decrease in mean arterial blood pressure beginning from the second week in comparison to the group receiving L-NAME alone (171). Interestingly blood pressure was totally restored by curcumin at the end of the experimental period. Furthermore, treatment of L-NAME rats with curcumin significantly restored the plasma nitrate/nitrite levels, and reduced oxidative stress and replenished antioxidant glutathione in renal tissue with partial restoration of normal redox status (171). Since persistent oxidative stress renders eNOS dysfunctional so that it no longer produces NO but O2*- (172), the effects on cellular redox balance support an antioxidative mechanism for curcumin. In addition, it has been demonstrated that curcumin exerted a protective effect in nephrectomy-induced hypertension by enhancing the adaptive antioxidant response modulated by Nrf2 (173).

In addition, curcumin was able to prevent L-NAME- or Angiotensin II-induced hypertension in the rat by lowering the expression of angiotensin II receptor type 1 (AT1R) in arteries so resulting in vasodilation and increase of vascular compliance $(171,174)$. Interestingly, the regulation of curcumin on AT1R protein expression seemed to occur at the transcriptional level as demonstrated in embryonic thoracic aortic smooth muscle cells (174). Involvement of renin-angiotensin axis was further confirmed in ICR mice since treatment with curcumin (50 $\mathrm{mg} / \mathrm{kg}$ body weight for 4 weeks) was significantly effective in reducing the blood pressure and inhibiting angiotensin-converting enzyme (ACE) activation and ACE mRNA expression when compared to untreated control mice (175). However, different strategies based on drug delivery systems, including adjuvants (i.e. piperine), liposomes, micronization and nanosystems), have been developed in order to increase CUR bioavailability and absorption 
(176). As to the hypertensive effect of curcumin, the pure compound encapsulated in Poly Lactic-co-Glycolic Acid (PLGA) nanoparticles at $5 \mathrm{mg} / \mathrm{kg} /$ day produced improvements in systolic blood pressure and left ventricular function similar to those of a free curcumin 100 $\mathrm{mg} / \mathrm{kg} /$ day in rats withy high-fat diet-induced hypertension (170).

Similarly, in male, hypertensive, heterozygous TGR(m-Ren2)27 rats, a transgenic model of the severe renin-angiotensin system (RAS)-dependent hypertension, a low dose of curcumin $(4.5 \mathrm{mg} / \mathrm{kg})$ administrated in hyaluronic acid-based nanocapsules, resulted in mild hypotensive effects, while the same dose of curcumin given as oil solution at the same dose was ineffective (177). One has to note that free curcumin up to the dose of $100 \mathrm{mg} / \mathrm{kg} /$ day for 4 weeks appeared unable to decrease in a statistically significant way arterial pressure values in stroke-prone spontaneously hypertensive rats, although it delayed the onset of stroke and increased the survival (178).

These findings all suggest that supplementation of curcumin in the daily diet may be useful for the prevention of hypertension and support its use as a valuable adjunct to conventional antihypertensive drugs.

\section{Endothelial function}

The endothelium is a single layer of cells providing the inner layer of blood vessels in the entire circulatory system. It plays a pivotal role in maintaining cardiovascular homeostasis, attenuating vascular inflammation, and in regulating blood pressure, cellular trafficking, and coagulation (179). Disruption of endothelial function, characterized by pro-coagulative, pro-inflammatory, and pro-vasoconstrictive features, is an early event in many pathologies including atherosclerosis, hypertension, diabetes, and hyperlipidemia (179, 180). Moreover, angiogenesis, consisting of the development of new blood vessels, is essential not only for embryonic growth but also later for physiological repair processes such as wound healing, post-ischemic tissue restoration, and the endometrial changes of the menstrual cycle (181). The equilibrium between angiogenesis and vascular regression is crucial for preserving the microvascular network in heart, brain, and other tissues. Further, it is thought that endothelial dysfunction and impaired nitric oxide (NO) bioavailability play a critical role in angiogenic incompetence (182).

Scientific evidence supports the therapeutic use of curcumin in cardiovascular diseases as it may improve endothelial function mainly by its anti-inflammatory and antioxidant properties, and the capability to alter NO bioavailability $(183,184)$.

The anti-inflammatory effects of curcumin have been attributed mainly to its ability to modulate NF-kB pathway in endothelial cells, as well as the MAP kinases JNK, ERK1/2, and p38, leading to a decrease in the expression of adhesion molecules, such as intercellular adhesion molecule-1 (ICAM-1), vascular cell adhesion molecule-1 (VCAM-1), and E-selectin, and thus reducing trans-endothelial monocyte migration (67) (figure 6). In particular, NF- $\kappa B$ pathway is a reactive oxygen species (ROS)-dependent cell signaling pathway whose activation is tightly regulated in order to protect the organism, and its over-activation seems to be often implicated in many diseases including inflammation, immune disorders, and cancer (185).

Recently, Chen et al. (186), using a model of human aortic endothelial cells (HAECs), have shown that curcumin protects from endothelial dysfunction and inflammation caused by degradation of poly-L-lactic acid (PLLA), used in the clinic to produce biodegradable coronary artery stents. Curcumin, in fact, reduced NF- $\mathrm{BB}$ and consequently VCAM-1 levels increased by PLLA exposure, and increased endothelial nitric oxide synthase (eNOS) levels. Previously, Lu et al. (187) prepared and administrated intravenously twice a week curcumin loaded nanoparticles in pigs after stent implantation. Curcumin nanoparticles accelerated endothelial cells restoration and endothelium function recovery, and thus the authors 


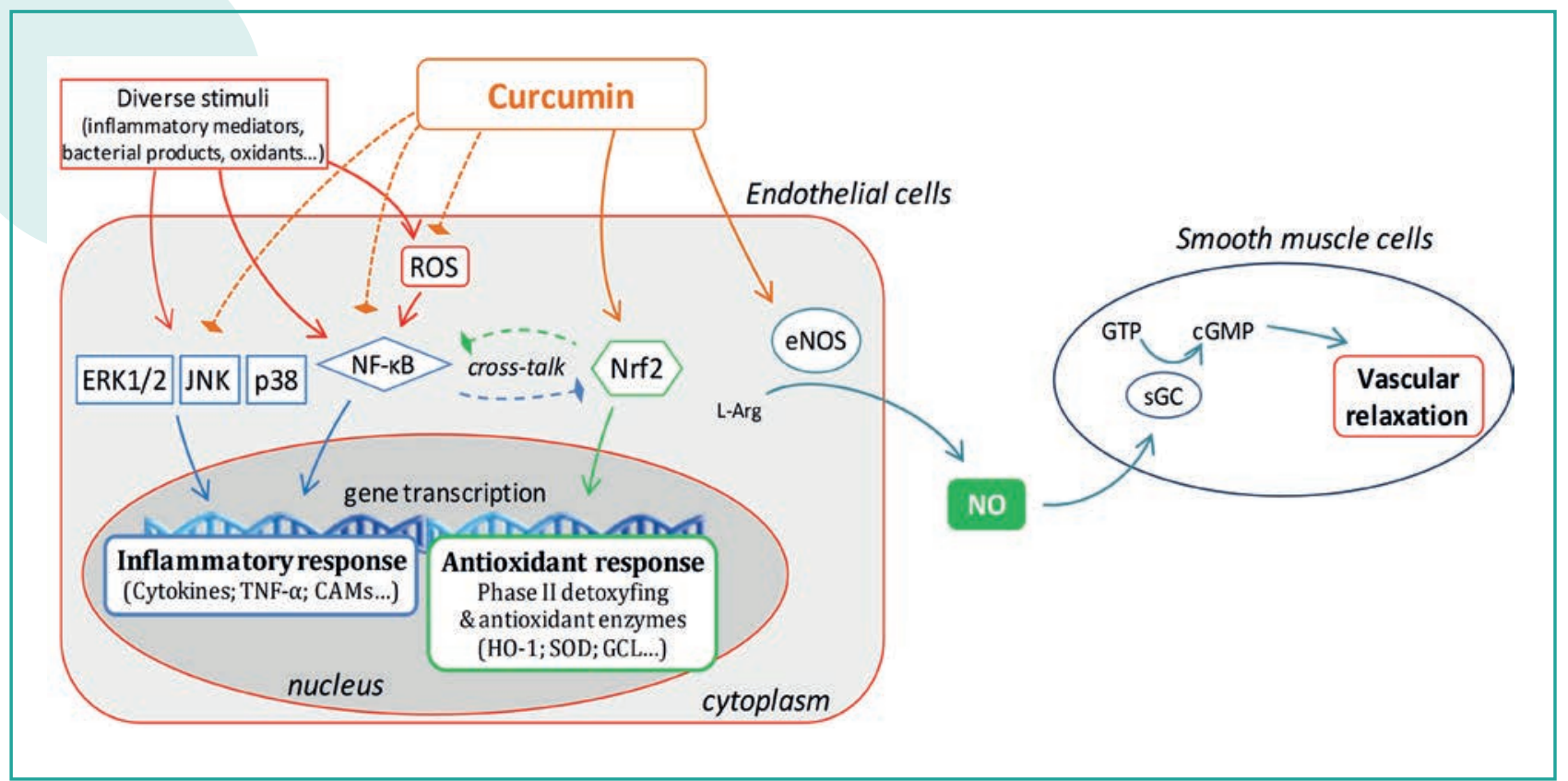

Figure 6. Effects of curcumin on endothelial dysfunction. Curcumin inhibits the pro-inflammatory ROSdependent NF- $\kappa B$ pathway and the MAPKs pathway, and to activates the Nrf2 pathway, thus inducing the expression of genes encoding for antioxidant and detoxification enzymes. Moreover, curcumin induces the endothelial formation of NO, and thus vascular relaxation. ARE, antioxidant responsive element; CAMs, cell adhesion molecules; cGMP, cyclic guanosine monophosphate; eNOS, endothelial NO synthase; ERK, Extracellular signal-regulated kinases; GCL, glutamate cysteine ligase; GTP, guanosine-50-triphosphate; JNK, c-Jun N-terminal kinases; HO-1, heme oxygenase-1; LPS, lipopolysaccharides; NO, nitric oxide; Nrf2, nuclear factor erythroid-2 (NF-E2)-related factor 2; p38 MAPK, p38 mitogen-activated protein kinases; ROS, reactive oxygen species; SGC, soluble guanylyl cyclase; SOD, superoxide dismutase; TNF- $\alpha$, tumor necrosis factor $\alpha$.

suggest they may potentially be an effective therapeutic alternative to reduce adverse events for drug-eluting stents. Furthermore, curcumin is a promising combined agent for the rescue of drug-eluting stents induced reendothelialization delay; in fact, it significantly reversed the detrimental effects of the anti-smooth muscle proliferation drug rapamycin in rat aortic endothelial cells through upregulating eNOS (188).

Zhang and Li (189) demonstrated curcumin anti-inflammatory activity in a high glucose-induced inflammatory injury model in rat thoracic aorta endothelial cells. Treatment with $10 \mu \mathrm{M}$ curcumin for $12 \mathrm{~h}$ inhibited high glucose-induced PI3K/Akt and NF-KB signaling pathway through inhibition of ROS, leading to a decrease in the protein expression of the proinflammatory cytokines IL-1 $\beta$, IL-6, and TNF- $\alpha$.
Moreover, Li et al. (190) reported the synergistic effect of curcumin and atorvastatin against endothelial dysfunction. In this model, liposomes modified using a targeting ligand (E-selectin-binding peptide) were used to co-deliver atorvastatin and curcumin to dysfunctional HAECs exposed to lipopolysaccharides (LPS) and overexpressing E-selectin. The treatment resulted in the suppression of E-selectin and ICAM-1. Furthermore, these findings were confirmed in an in vivo model since the administration of liposomes co-loaded with atorvastatin and curcumin in ApoE knockout $\left(A_{\left.p o E^{-/}\right)}\right.$mice reduced foam cell formation and secretion of inflammatory factors (IL-6 and MCP-1) by blocking monocyte migration into the intima.

The possible mechanism of action underlying the protective activity of curcumin against en- 
dothelial dysfunction seems to be related to its antioxidant properties and, in particular, to its ability to induce nuclear factor erythroid 2-related factor 2/antioxidant responsive element (Nrf2/ARE) signaling pathway $(183,191)$ (figure 6). Nrf2 pathway regulates both the basal homeostatic as well as the inducible expression of many genes encoding for antioxidant and detoxification enzymes, such as heme oxygenase-1 (HO-1), superoxide dismutase (SOD), and glutamate cysteine ligase (GCL), a key enzyme in GSH biosynthesis, and plays a key role in protecting cells upon oxidative stress conditions $(192,193)$. Nrf2 pathway, in particular, has been reported to protect against oxidative stress-induced endothelial dysfunction and atherosclerosis (194, 195). Moreover, various phytochemicals, including curcumin, are able to suppress NF-kB and activate Nrf2 pathway (196-198), supporting the hypothesis of a putative crosstalk between these signaling pathways (figure 6). In this context, Ouyang et al. (199) reported that curcumin protects human umbilical vein endothelial cells (HUVECs) from $\mathrm{H}_{2} \mathrm{O}_{2}$-induced oxidative stress. Cells pretreatment with curcumin (40 and $50 \mu \mathrm{M})$ for $12 \mathrm{~h}$ enhanced SOD and GSH levels and reduced those of ROS and malondialdehyde, supporting the role of curcumin in regulating oxidative homeostasis in HUVECs by stimulating antioxidant enzymes.

In view of a possible use of curcumin for actively supporting the survival and function of corneal endothelial cells (CECs) monolayers after transplantation, Li et al. (200) showed that curcumin-loaded lipid-poly(lactic-co-glycolic acid) (PLGA) hybrid microparticles are capable of protecting CECs from oxidative stress-induced cell death via modulating Nrf2 pathway and suppressing the secretion of pro-inflammatory cytokines by macrophages. The delivery system used in this study allowed overtaking the poor aqueous stability of curcumin and its short curcumin persistence, significantly ameliorating its therapeutic efficiency.

Furthermore, Lan et al. (178) have reported the preventive effect of curcumin $(100 \mathrm{mg} / \mathrm{kg} /$ day for 4 weeks) on stroke in stroke-prone spontaneously hypertensive rats, by improving endothelial-dependent relaxation of carotid arteries and attenuating oxidative stress, as demonstrated also measuring ROS and $\mathrm{NO}$ levels in plasma and basilary arteries.

As reported by Wang and Chen (201) in a recent review, curcumin shows dual effects on angiogenesis, showing anti- as well as pro-angiogenic activity, and it has been speculated it may depend on the different microenvironments and on curcumin dosage, with pro-angiogenic effects at a lower doses and anti-angiogenic at higher doses.

Various studies on different in vitro and in vivo animal models reported the potential anti-angiogenic role of curcumin in different types of pathologies, in particular cancer $(183,201$, 202), but also endometriosis, liver fibrosis (202), and hemophilic arthropathy (203). However, a proangiogenic activity of curcumin has also been reported. In particular, various studies reported curcumin wound healing properties, due to its capability to stimulate angiogenesis through increasing the expression of vascular endothelium growth factor (VEGF) (204) and also favored by its good anti-inflammatory, antibacterial, and antioxidant activity $(201,205)$. Curcumin employment in wound healing may be ameliorated through the development of innovative materials (206), such as mesoporous silica particles, heparin-grafted aligned PLGA nanofibers, chitosan nanoparticles, human epidermal growth factor-curcumin bandage bioconjugate loaded with mesenchymal stem cells, chitosan nanoparticles, nanostructured lipid carriers containing epidermal growth factor. These studies have been developed by means of in vitro cell-based models (HUVEC endothelial cells, NIH 3 T3 fibroblasts, $\mathrm{HaCaT}$ keratinocytes) and in vivo experimental models on health and diabetic rodents $(119,207-212)$.

All these data support curcumin nutraceutical use for improving endothelial function thanks to its anti-inflammatory and antioxidant properties mainly through the regulation of the cross- 
talk between Nrf2 and NF-kB pathways, and to its ability to increase nitric oxide availability (figure 6). Finally, curcumin shows dual effects on angiogenesis, showing both anti-angiogenic activities in different types of cancer, as well as pro-angiogenic effects giving curcumin a high potential in improving wound healing.

\section{CENTRAL NERVOUS SYSTEM}

The neurological effects of curcumin have been extensively investigated at the central nervous system (CNS) level. Curcumin has been clinically evaluated in patients with depression as well as in patients with neurodegenerative diseases such as Alzheimer's diseases $(213,214)$. However, the evidence of efficacy is far from being compelling.

This chapter collects the molecular mechanisms and preclinical studies of curcumin in the main pathologies of CNS, summarizing recent reviews and describing the most recent experimental evidence.

\section{Stress and depression}

Depression is a multifactorial disease that combines genetic predisposition with environmental factors, among which chronic stress plays an important role. Ramaholimihaso et al. extensively reviewed the different potential mechanism of action of curcumin in major depressive disorders (215) and their major findings are reported in brief. One of the main molecular causes of the disease has been hypothesized the deficiency of monoamines (dopamine, serotonin, noradrenalin), currently the basis of the major antidepressant therapies. In vitro and animal studies showed that curcumin enhances monoamines in the central nervous system, inhibiting monoamine oxidase (MAO) and increasing the expression of serotonin receptors. Curcumin reduced the inflammation-induced by overexpression of indoleamine 2,3 dioxygenase, an enzyme linked to tryptophan depletion which influences the availability of this precursor for the synthesis of serotonin. In addition, curcumin inhibit- ed glutamate release, probably acting on the GluN2B subunit of NDMA receptors and consequently increasing BDNF levels. Curcumin showed neuroprotective effects by increasing the production of different neurotrophic factors, in particular BDNF (216).

The inflammatory state plays a role in depressive pathology and curcumin treatment reduced depressive behaviors in animals treated with LPS, thanks to the previously reported anti-inflammatory properties, creating a link with intestinal hyperpermeability (brain-gut axis). Similar effects in inflammatory markers were seen by de Gomes et al. (217). The contribution of the anti-inflammatory activity was also observed in animal models of chronic stress thanks to the reduction of NLRP3 inflammasome activation, resulting in lowering of nitric oxide (NO) and IL-1 $\beta$ levels. NLPR3 activation is also influenced by reduced intracellular potassium levels, mediated by $\mathrm{P} 2 \mathrm{X} 7$ purinergic receptors and curcumin suppressed their activation. Furthermore, curcumin limited depressive symptoms in cortisol-treated animals and reduced the size of the adrenal gland in rats, one of the glandular symptoms of depression. Finally, curcumin's ability to relieve insulin resistance appears to be linked to decreased depressive-like symptoms in vivo.

Another possible mechanism involved in depression, not discussed in the described review, is the reduction of oxidative stress by the activation of NRF-2 signaling pathway by curcumin $(218,219)$. Curcumin also reduced depressive-like symptoms in animal treated with rotenone, a toxin associated to Parkinson's disease (220), and mercuric chloride (221).

\section{Neurodegenerative diseases}

\section{Alzheimer's disease}

The molecular basis for the neuroprotective role of curcumin in Alzheimer disease (AD) have been widely investigated and revised. The most characterized properties of curcumin are the direct interaction with $\beta$-amyloid and tau fibrils aggregation, and the acetylcholin- 
esterase (AchE) inhibition (222). Not surprisingly for these targets, curcumin nowadays represents a scaffold for novel drugs design (223-225). During the last years, curcumin and its derivatives reached even greater attention for additional neuroprotective effects, potentially useful in the multitarget approach for $A D$ treatment. Several authors demonstrated that curcumin may counteract oxidative stress and neuroinflammation in $A D$ models by inducing autophagy: a fundamental mechanism was identified in the enhancement of AMPK activity (226-230). Moreover, curcumin may promotes autophagic proteins and their retrograde axonal transport (231).

The effect on AMPK, along with PPAR $\gamma$ agonism and BACE-1 inhibition, may explain how curcumin activates the transcription factor NRF2 , involved in neuroprotection and antioxidant defense (232-237). Again, the same targets are clearly included in the anti-inflammatory mechanism of curcumin, which showed to impair the activity of NF-KB and the inflammasome machinery leading to cytokines reduction (238243). In analogy, curcumin favors SIRT-1 activity and the related post-transcriptional modifications, thus enhancing cell metabolism and reducing inflammation at the central level (226, 244). The inhibition of miR-146a and miR-155 has been suggested as further post-transcriptional effect of curcumin with anti-inflammatory consequences $(245,246)$. According to recent studies, the JAK/STAT signal inhibition in microglia represents another potential anti-inflammatory target (242).

AMPK/SIRT-1 activation by curcumin is also involved in the prevention of $\beta$-amyloid production through the activity of $\alpha$-secretase; however, curcumin impairs also the $\beta$-secretase activity, thus reducing the levels of $\beta$-amyloid precursor (APP) $(226,247)$. Another important target of curcumin is GSK-3 $\beta$, involved in fibrils deposition and the consequent cytotoxic events. Curcumin counteracted GSK-3 $\beta$ by activating Akt/PI3K pathway at the upstream level, which, as known, modulates the AMPK/ NRF-2 pathway (248-250). GSK-3 $\beta$ inhibition accounts for the activation of $\mathrm{Wnt} / \beta$-catenin pathway, thus explaining the effect of curcumin on hippocampal neurogenesis and cognitive function $(251,252)$. The modulation of Akt is also correlated with the positive effect of curcumin on BDNF levels $(253,254)$, neuronal proliferation and differentiation $(255,256)$, and dendritic spines preservation $(257,258)$.

As revised by Pluta et al. (259) the biological activity of curcumin protects brain injury in ischemia-reperfusion models of AD. In addition, the beneficial effect of curcumin on memory deficit and cognitive impairment may involve metabolic effects such as the enhancement of glucose uptake and lactate levels in brain $(260,261)$. Finally, Sun et al reported that curcumin and microbiota were bidirectionally influenced in $A D$ mice models (262).

\section{Parkinson disease}

In recent years many reviews have summarized the curcumin's beneficial effects on Parkinson's disease (PD) $(226,263)$. The neuroprotective role of curcumin on dopaminergic neurons is widely studied in various models of PD, showing an improvement of oxidative stress and neuroinflammation.

A great number of studies showed that curcumin increased the tyrosine hydroxylase and dopamine levels, the number of surviving dopamine neurons, the level of $\mathrm{Bcl}-2$ and the protein expression of TFEB, LAMP2A, and LC3-II, while reduced nitric oxide synthase, Bax, $\alpha-S y n$, and caspase 3 expression (253, 264-266). Others neuroprotective pathways modulated by curcumin are: the cholinergic system via an $\alpha 7$-nicotinic acetylcholine receptor ( $\alpha 7-n A C h R)-m e d i a t e d ~ m e c h a n i s m ~(267)$; the histone acetylation by targeting of histone acetyltransferases (HATs), resulting in the reduction of severity of L-DOPA-induced dyskinesia (268); the up-regulation of HSP90 studied in SH-SY5Y cells (46); and the correction of Akt/GSK-3 $\beta$ signaling (269).

Two recent in vivo studies on neurotoxic metal elements, revealed the beneficial effects of curcumin on dopaminergic and astroglial alterations 
caused by chronic $\mathrm{Cu}$ or $\mathrm{Al}$ exposition in rats, which reinstated both tyrosine hydroxylase expression and locomotor performance $(270,271)$. In vitro, arsenic induces toxicity decreasing cell survival rate and enhancing the loss of mitochondrial membrane potential. Pre-treatment with curcumin significantly decreased arsenic effects, probably by antioxidant and anti-apoptotic mechanisms (272).

A new potential protective effect of curcumin on dopamine neurons is the regulation of autophagy, by decreasing the BAX/BCL2 ratio and increasing of LC3 and ATG10 expression (two factors involved in the formation of autophagosome) (273), by regulation of TFEB export signaling via inhibition of glycogen synthase kinase-3b (GSK-3b) (234), and by activation of autophagy in an ROS-dependent manner (255).

Some authors demonstrated a key role of curcumin in reducing oxidative stress, for example lowering the level of ROS (274) and oxidized proteins (275), and through modulation of the NRF-2/HO-1 pathway (234).

Furthermore, curcumin prevented the LPS-induced upregulation of the protein activity of $N F-\kappa B$, proinflammatory cytokines (TNF- $\alpha$, IL$1 \beta$, and IL-1 $\alpha$ ), and inducible nitric oxide synthase (iNOS). As already reported in other studies curcumin regulates molecules of the intrinsic apoptotic pathway ( $\mathrm{Bax}, \mathrm{Bcl}-2$, caspase 3 , and caspase 9), improves the glutathione system, and prevents the formation of $\alpha$-synuclein aggregates in the dopaminergic neurons (276). In a LPS-induced BV-2 microglial cells, the administration of curcumin increased the production of the anti-inflammatory cytokines, IL-4 and IL-10, and regulated neuroinflammatory reactions by eliciting anti-inflammatory responses in microglia through JAK/STAT/SOCS signaling pathway (242). Moreover, curcumin enhanced microglia polarization by activating the AMP-activated protein kinase (AMPK) signaling pathway (277).

One of the more interesting, but still relatively unknown, mechanisms of curcumin is related to $\alpha$-synuclein aggregation/disaggregation and oligomer-induced toxicity in dopaminergic neurons, which may prevent Lewy Bodies accumulation. Curcumin inhibited the $\alpha$-synuclein aggregation in rodents treated with LPS or rotenone, through inhibition of oxidative stress generation, replenishing GSH levels, as well as preventing the inflammatory response $(276,278)$. Curcumin efficiently prevented mitochondrial Type 1 Hexokinase (HKI) and ROS enhancement induced by $\alpha$-synuclein fibrillation products (279). In addition, curcumin induced the degradation of amyloidogenic proteins, including $\beta$-amyloid precursor protein and $\alpha$-synuclein, through the TFEB-autophagy/lysosomal pathway, the inhibition of GSK-3b, and the increase of antioxidant genes (234). Moreover a molecular dynamics method showed that curcumin binds the Non-Amyloid-Component (NAC) domain of $\alpha$-synuclein, reducing protein aggregation (280). Finally, Doythchinova et al. demonstrated the inhibitory activity of curcumin on $A \beta$ aggregation at atomic level: the molecule intercalates among the $A \beta$ chains, making peptides less flexible and more disordered, and reducing non-native contacts and $\mathrm{H}$-bonds (281).

\section{Huntington disease}

Differently from $A D$, the evidence on curcumin in Huntington disease (HD) is less documented. However, the bioactivity of curcumin referring to autophagy induction, anti-inflammatory effect, and antioxidant defense at central level was suggested as plausibly useful against HD (228, 282-290). Despite the scarcity of in vivo demonstrations, curcumin was reported to impair the misfolding of huntingtin protein, in analogy with the well-established effect on $\beta$-amyloid (289, 291-295). Moreover, Pepe et al. recently demonstrated that nano-sized curcumin prevented huntingtin-mediated apoptosis in striatal derived cells (296). Elifani and Gharaibeh reported an ameliorated phenotype in HD murine models after oral administration of curcumin: in line with the scientific literature, both the authors observed the activation of pathways involved in BDNF expression, such 
as TrkB, Erk, and Akt $(292,297)$. Moreover, the authors investigated the impact of curcumin on gastrointestinal disturbs resembled in the R6/2 mice model of $H D$, which cause weight loss and cachexia: the authors observed a recovery in body weight and intestinal function. On the other side, Khyati et al. suggested a possible beneficial effect of curcumin on disturbed circadian rhythm occurring in HD (298). In Drosophila, the dietary administration of curcumin led to the normalization of the transcriptional pattern and the recovery of the locomotion ability and exclusion behavior, similarly to melatonin. Such epigenetic effect of curcumin on the biological clock was already reported in aging rats with suprachiasmatic nuclei lesions and may correlate with SIRT-1 activation (299).

\section{Multiple sclerosis}

Multiple sclerosis is an autoimmune disease of the central nervous system, characterized by a chronic inflammatory condition. CD4 ${ }^{+} \mathrm{T}$ cells, especially Th17 lymphocytes, play a crucial role in the pathophysiology of multiple sclerosis and participate in the disruption of the blood brain barrier, demyelination, and neuronal damages. A recent review collected the main molecular targets modulated by curcumin in experimental model of the disease (300). The described effects of curcumin included a reduction in proinflammatory cytokines (such as IFN- $\gamma, I L-1 \beta, I L-6, I L-12, I L-17, I L-23$, and TGF- $\beta$ ), caused by limited activation of NFкВ, MAPK, and JAK-STAT pathways, and a reduced infiltration of inflammatory cells in the central nervous system (decreasing CXCL1 and CXCL2). In turn, the reduction of inflammation prevents the disruption of the bloodbrain barrier (modulating ZO-1 and reducing ROS). In addition, curcumin protected oligodendrocytes from apoptosis, by inhibiting intrinsic apoptotic pathway and mitochondrial stress, and axon degeneration reducing JNK phosphorylation and NO release (300).

Recent studies investigated the effects of curcumin in experimental models of encephalo- myelitis. Curcumin reduced the expression levels of pro-inflammatory cytokines and enhanced the activity of anti-oxidant enzymes in the corpus callosum of mice (301) and influenced AKT/mTOR signaling pathway inducing autophagy (302), a mechanism that, if altered, can lead to neuronal damage. Another study supported the protection of oligodendrocytes by intraperitoneal administration of dendrosomal nano-curcumin in cuprizone treated mice, preserving myelin content in the corpus callosum (303) and this formulation also enhanced oligodendrogenesis in vitro (304).

Furthermore, in vitro curcumin reduced the activation of $\mathrm{CD}^{+}{ }^{+} \mathrm{T}$ cells (Th1, Th17, and Treg) and influenced their proliferation promoting apoptosis (305).

\section{Ischemic stroke}

Curcumin is involved in the treatment of post-ischemic neurodegeneration and in the prevention of neurodegenerative changes development after cerebral ischemia (306).

Curcumin promotes neuron survival in in vivo and in vitro models of cerebral ischemia reperfusion (I/R) injury, exerting neuroprotective effects against ischemia injury. It was demonstrated that curcumin inhibits ischemia-induced mitochondrial apoptosis via restricting Bax and caspase- 3 activation and increasing $\mathrm{Bcl}-2$ protein levels $(307,308)$. Curcumin improved nerve damage symptoms and infarct volume, reduced brain water content, relieved neuronal apoptosis acting in the MEK/ERK/CREB pathway, induced the expression of P-MEK, p-ERK, p-cREB, Bcl-2, and reduced Bax levels (309). Moreover curcumin exhibited a protective function through PKS-q signaling by reducing blood-brain barrier dysfunction (310). Other studies demonstrated that curcumin protected cells by inhibiting apoptosis, balancing the Bax/Bacl2 protein expression, and attenuating autophagic activities mediating PI3K/AKT pathway activation (311). Curcumin suppressed inflammatory reactions and oxidative stress by regulating the TLR4/p38/MAPK pathway, downregulating LC3-II/LC3-I, IL-1, 
TLR4, p-38, p-p38 (312), IL-6, NF-kB, Mcp-1, and F2IsoP (313). Other mechanisms involved in curcumin neuroprotection are the novel flotIlin-1 and the ERK1/2 pathway (314).

Curcumin showed positive effects in the poststroke depression (PSD), attenuating behavioral disorders associated with the disease. The $\mathrm{Ca}^{2+}$ accumulation and the inflammatory response associated with PSD were blocked by curcumin, inhibiting the activity of the P2X2 receptor, which then deactivated $\mathrm{Ca}^{2+}$ channel-mediated inflammatory response associated with PSD progression (315). Furthermore, curcumin enhanced the growth arrest-specific transcript 5 (GAS5), which contributed to the activation of the BDNF/Trk $\beta$ signaling pathway, promoting the expression of synaptic-related proteins. These results revealed a novel mechanism of curcumin on PSD through the GAS5/ miR-10b/BDNF regulatory axis (316).

\section{Amyotrophic lateral sclerosis}

The potential interest of curcumin for amyotrophic lateral sclerosis (ALS) was recently revised by Buratti et al. (317). The author remarked that ALS was considered a proteinopathy after the important discovery of TAR DNA binding protein-43 (TDP-43) aggregates in ALS patients. Consequently, several studies were conducted on curcumin as neurotoxic protein aggregates inhibitor. Curcumin counteracted TDP-43 aggregation and the related cytotoxicity in several in vitro models. Moreover, dimethoxy-curcumin prevented the TDP43-induced abnormalities in action potentials in motor neuron cell lines. Once again, the main suggested mechanisms were the induction NRF-2 activity and the inhibition of protein aggregation in motor neurons models (318). Despite curcumin may act through different neuroprotective mechanisms, the research on ALS gives only few results, thus underlining the necessity of more pre-clinical studies.

\section{Epilepsy}

Epilepsy is a neurological disorder characterized by recurrent and spontaneous seizures, often associated with cognitive and neurobiological consequences. A prolonged state of seizures can induce the activation of an inflammatory state that induces a greater predisposition and lead to neuronal death. In fact, oxidative stress and inflammatory state are the two main factors involved in epilepsy. As reviewed by Dhir et al. (319), curcumin thanks to its anti-inflammatory and antioxidant activities showed protective and therapeutic effects in this field.

In acute animal model of seizures, curcumin was found to elevate the seizure threshold in current electroshock test mice, similarly to phenytoin. Curcumin showed anticonvulsant effect in rats challenged with pilocarpine, by reducing oxidative markers (also in chronic models). The antioxidant mechanisms are also the basis of curcumin protection from kainic acid-induced seizures in rats, where a reduced percentage of convulsion and an increased latency to convulsions onset were found.

In chronic models, curcumin prevented seizures in rats induced by $\mathrm{FeCl}_{3}$, a model mimicking human post-traumatic epilepsy, probably due to anti-inflammatory properties and by increased expression of voltage-activated $\mathrm{Na}^{+}$channel subtypes (320). Curcumin also increased the expression of ion-channel protein mutations CACNA1A (presynaptic $\mathrm{CA}^{2+}$ channel) and GABRD (post-synaptic $\mathrm{Cl}^{-}$channel), channels mutations associated with epilepsy, in which related protein expressions are reduced during $\mathrm{FeCl}_{3}$ treatment (321).

In addition, curcumin protected animals challenged with repeated chemical (pentylenetetrazol) and electrical insults, eventually protecting from cognitive decline, by a mechanism involving antioxidant effects and, in the case of pentylenetetrazol, by L-arginine nitric oxide pathway. A recent study showed a reduction of TNF- $\alpha$ by curcumin in pentylenetetrazol-treated mice, and upregulation of klotho and erythropoietin as neuroprotective factors (322).

In a kainic acid rat model, curcumin prevented activation of astrocytes and neuronal death, and a recent study showed a mechanism in- 
volving the Bcl2 family and P38 MAPK pathways (323). The anti-epileptic effects were probably associated, according to the authors, to lower IL10RB, CXCL17, and nicastrin levels. Other possible mechanisms involved in the antiepileptic effects of curcumin are the regulation of calcium and aquaporin-4 channels, the increase of GABA inhibitory neurotransmitter, and the inhibition of mTOR pathway (324) and glutamate, as previously described. Recent studies also showed an anti-seizure effect of curcumin in pentylenetetrazol treated zebrafish (325).

\section{SKIN}

Clinical data suggest that curcumin may play a role in skin health management and might be beneficial in a number of skin diseases such as alopecia, atopic dermatitis (eczema), acne, androgenetic facial photo-ageing, oral liken planus, pruritus, psoriasis, vitiligo, and radiodermatitis (17).

Curcumin has been studied for its beneficial effects in various skin diseases upon topical and oral administration, mainly based on its antibacterial, anti-inflammatory, and antioxidant/scavenging activity, with in vitro active concentrations in the micromolar range (326). As low aqueous solubility, poor tissue absorption, rapid metabolism, and short plasma halflife limit its topical delivery, recent research has focused on developing new technologies to increase skin absorption.

Experimental in vitro and animal model studies indicate beneficial effects of curcumin in psoriasis, a chronically relapsing inflammatory skin disease: modulation of inflammatory mediator release from $T$ cells and improvement of skin lesions have been repeatedly shown. Recently, the use of cellulose nanofiber film hybridized with curcumin-loaded lipid nanocarriers (327), a nanohydrogel system (328), curcumin-loaded silica particles (329), were reported to increase skin delivery and significantly improve psoriasis-like lesions in imiquimod-treated mice. The efficacy of curcumin has also been shown in wound healing models. Bacterial growth, inflammation and oxidative stress all interfere with the healing process, potentially causing a wound to become chronic. The addition of curcumin to different types of polymer-based dressings or nanofibers has been investigated in preclinical studies, showing improved effects in facilitating healing and preventing/reducing bacterial invasion (205, 206). Beneficial effects of curcumin preparations have been reported in animal models of diabetes-associated wounds $(212,330,331)$. Among these, pre-treatment with curcumin has been proposed to improve the healing activity of stem cells on diabetic rat wounds $(210,332)$. Evidence obtained in humans indicate that curcumin's vasal activity on peripheral arterioles might be beneficial in reducing face redness and photodamage (16), and indeed curcumin has been proposed for the treatment of rosacea and acne (333). A liposomal gel preparation containing curcumin and lauric acid has been shown to reduce bacterial growth of $P$. acnes and to reduce comedone counts and cytokines in a rat ear model of acne (334). The antimicrobial activity coupled with the inhibition of several inflammatory pathways associated with hyper keratinization make curcumin a possible candidate for new plant-based treatments of acne (335).

In vitro antileishmanial activities have also been reported for curcumin-loaded Self-Emulsifying Drug Delivery System (SEDDS), laying the basis for the investigation of curcumin use in cutaneous and muco-cutaneous leishmaniasis (336). Vitiligo is another oxidative stress-related skin condition, where the use of antioxidants has been proposed to protect melanocytes from becoming dysfunctional. In this context, curcumin has been shown to be effective in protecting human perilesional keratinocytes from oxidative stress in vitro (337).

Photodamage is a growingly relevant issue in dermatology, in view of raising incidence of skin cancer and photoaging in humans. Curcumin nanoparticles have been shown to reduce erythema, scale and local cytokine release 
in UVB-irradiated mice (338). Protective effects have also been reported in vitro towards UVA irradiation cellular effects in human dermal fibroblasts (339).

In conclusion, much research work is currently devoted to evaluating the efficacy of curcumin in skin disorders. The use of advanced delivery techniques for topical use has the potential to re-juvenate the traditional use of turmeric for dermatological diseases.

\section{CONCLUSIONS}

Curcumin has been tested in a multitude of preclinical studies, showing beneficial effects in several pathological conditions. Among the most promising pharmacological properties, anti-inflammatory and antioxidant effects cover a relevant position; the effect may be due to the modulation, at the molecular levels, of several inflammatory mediators which include NF$\kappa \mathrm{B}$ and Nrf2 whereas beneficial effects against metabolic syndromes seems to be linked to PPAR $\gamma$ modulation. However, the overall mode of action is multitarget since curcumin interacts with a variety of nuclear factors, enzymes, and growth factors. Despite beneficial effects demonstrated in different diseases, the avail-

\section{REFERENCES}

1. Kotha RR, Luthria DL. Curcumin: biological, pharmaceutical, nutraceutical, and analytical aspects. Molecules. 2019;24(16):2930.

2. Tsuda T. Curcumin as a functional food-derived factor: degradation products, metabolites, bioactivity, and future perspectives. Food function. 2018;9(2):705-14.

3. Nelson KM, Dahlin JL, Bisson J, Graham J, Pauli GF, Walters MA. The essential medicinal chemistry of curcumin: miniperspective. Journal of medicinal chemistry. 2017;60(5):1620-37.

4. Prasad S, Gupta SC, Tyagi AK, Aggarwal BB. Curcumin, a component of golden spice: from bedside to bench able literature states that the oral absorption of curcumin, administered as component of turmeric extracts, is poor, with plasma levels that are in the low nanomolar range after taking doses of the extract of 4-12 g. These findings suggest that the main metabolites of curcumin previously detected in human plasma, which include the sulfate and glucuronide derivatives, may contribute to the health effects following curcumin intake.

However, different drug delivery methods have been set up to improve curcumin bioavailability, including inclusion in phytosomes, liposomes, and nanoparticles. Taken together, these methods have improved plasmatic levels of curcumin, and should be considered for future clinical studies.

\section{ACKNOWLEDGMENTS}

The authors thank Prof. Angelo Antonio Izzo for the critical reading of the paper and useful suggestions.

\section{CONFLICT OF INTERESTS}

The authors declare that they have no conflict of interests. and back. Biotechnology advances. 2014;32(6):1053-64.

5. Goel A, Kunnumakkara AB, Aggarwal BB. Curcumin as "Curecumin": from kitchen to clinic. Biochemical pharmacology. 2008;75(4):787-809.

6. Jitoe-Masuda A, Fujimoto A, Masuda T. Curcumin: from chemistry to chemistry-based functions. Current pharmaceutical design. 2013;19(11):2084-92.

7. Aggarwal BB, Sundaram C, Malani N, Ichikawa H. Curcumin: the Indian solid gold. The molecular targets and therapeutic uses of curcumin in health and disease. 2007:1-75.

8. Bos $\mathrm{R}$, Windono $\mathrm{T}$, Woerdenbag $\mathrm{HJ}$, Boersma $Y L$, Koulman A, Kayser $O$. 
HPLC-photodiode array detection analysis of curcuminoids in Curcuma species indigenous to Indonesia. Phytochem Anal. 2007;18(2):118-22.

9. Li R, Xiang C, Ye M, Li H-F, Zhang X, Guo $D-A$. Qualitative and quantitative analysis of curcuminoids in herbal medicines derived from Curcuma species. Food Chemistry. 2011;126(4):1890-5.

10. Clifford T, Acton JP, Cocksedge SP, Davies KAB, Bailey SJ. The effect of dietary phytochemicals on nuclear factor erythroid 2-related factor 2 (Nrf2) activation: a systematic review of human intervention trials. Mol Biol Rep. 2021;48(2):1745-61.

11. Memarzia A, Khazdair MR, Behrouz $S$, Gholamnezhad Z, Jafarnezhad M, Saadat $\mathrm{S}$, Boskabady $\mathrm{MH}$. Experimental and clinical reports on anti-inflammatory, antioxidant, and immunomodulatory effects of Curcuma longa and curcumin, an updated and comprehensive review. Biofactors. 2021.

12. Salehi B, Rodrigues $C F$, Peron $G$, et al. Curcumin nanoformulations for antimicrobial and wound healing purposes. Phytother Res. 2021.

13. Hallajzadeh J, Milajerdi A, Kolahdooz F, Amirani E, Mirzaei H, Asemi Z. The effects of curcumin supplementation on endothelial function: A systematic review and meta-analysis of randomized controlled trials. Phytother Res. 2019;33(11):2989-95.

14. Gagliardi S, Morasso C, Stivaktakis P, Pandini C, Tinelli V, Tsatsakis A, Prosperi D, Hickey M, Corsi F, Cereda C. Curcumin Formulations and Trials: What's New in Neurological Diseases. Molecules. 2020;25(22).

15. Carrizzo A, Izzo C, Forte $M$, Sommella E, et al. A Novel Promising Frontier for Human Health: The Beneficial Effects of Nutraceuticals in Cardiovascular Diseases. Int J Mol Sci. 2020;21(22).

16. Barbalho SM, de Sousa Gonzaga HF, de Souza GA, de Alvares Goulart R, de Sou- sa Gonzaga ML, de Alvarez Rezende B. Dermatological effects of Curcuma species: a systematic review. Clin Exp Dermatol. 2021.

17. Pagano E, Romano B, Izzo AA, Borrelli F. The clinical efficacy of curcumin-containing nutraceuticals: An overview of systematic reviews. Pharmacol Res. 2018;134:79-91.

18. Zheng B, McClements DJ. Formulation of More Efficacious Curcumin Delivery Systems Using Colloid Science: Enhanced Solubility, Stability, and Bioavailability. Molecules. 2020;25(12):2791.

19. Priyadarsini KI. Photophysics, photochemistry and photobiology of curcumin: Studies from organic solutions, bio-mimetics and living cells. Journal of Photochemistry and Photobiology C: Photochemistry Reviews. 2009;10(2):81-95.

20. Priyadarsini KI. The chemistry of curcumin: from extraction to therapeutic agent. Molecules. 2014;19(12):20091-112.

21. Manolova $Y$, Deneva $V$, Antonov L, Drakalska E, Momekova D, Lambov $N$. The effect of the water on the curcumin tautomerism: A quantitative approach. Spectrochimica Acta Part A: Molecular and Biomolecular Spectroscopy. 2014;132:815-20.

22. Bachmeier BE, Mohrenz IV, Mirisola V, Schleicher E, Romeo F, Höhneke C, Jochum M, Nerlich AG, Pfeffer U. Curcumin downregulates the inflammatory cytokines CXCL1 and -2 in breast cancer cells via NFkappaB. Carcinogenesis. 2008;29(4):779-89.

23. Bharti AC, Donato N, Aggarwal BB. Curcumin (diferuloylmethane) inhibits constitutive and IL-6-inducible STAT3 phosphorylation in human multiple myeloma cells. J Immunol. 2003;171(7):3863-71.

24. Srivastava NS, Srivastava RAK. Curcumin and quercetin synergistically inhibit cancer cell proliferation in multiple cancer cells and modulate $\mathrm{Wnt} / \beta$-catenin signaling and apoptotic pathways in A375 cells. Phytomedicine. 2019;52:117-28. 
25. Killian $\mathrm{PH}$, Kronski $\mathrm{E}$, Michalik KM, et al. Curcumin inhibits prostate cancer metastasis in vivo by targeting the inflammatory cytokines CXCL1 and -2. Carcinogenesis. 2012;33(12):2507-19.

26. Zhou T, Wang Y, Liu M, et al. Curcumin inhibits calcification of human aortic valve interstitial cells by interfering NF$\kappa B, A K T$, and ERK pathways. Phytother Res. 2020;34(8):2074-81.

27. Hong J, Bose M, Ju J, et al. Modulation of arachidonic acid metabolism by curcumin and related $\beta$-diketone derivatives: effects on cytosolic phospholipase A 2 , cyclooxygenases and 5-lipoxygenase. Carcinogenesis. 2004;25(9):1671-9.

28. Zhou H, Beevers CS, Huang S. The targets of curcumin. Curr Drug Targets. 2011;12(3):332-47.

29. Kunnumakkara AB, Bordoloi D, Padmavathi G, Monisha J, Roy NK, Prasad S, Aggarwal BB. Curcumin, the golden nutraceutical: multitargeting for multiple chronic diseases. $\mathrm{Br} \mathrm{J}$ Pharmacol. 2017;174(11):1325-48.

30. Giordano A, Tommonaro G. Curcumin and Cancer. Nutrients. 2019;11(10).

31. Liczbiński P, Michałowicz J, Bukowska B. Molecular mechanism of curcumin action in signaling pathways: Review of the latest research. Phytother Res. 2020;34(8):1992-2005.

32. Sethi G, Tergaonkar V. Potential pharmacological control of the NF-kB pathway. Trends Pharmacol Sci. 2009;30(6):313-21.

33. Pearson G, Robinson F, Beers Gibson $T$, et al. Mitogen-activated protein (MAP) kinase pathways: regulation and physiological functions. Endocr Rev. 2001;22(2):153-83.

34. Martini M, De Santis MC, Braccini L, Gulluni F, Hirsch E. PI3K/AKT signaling pathway and cancer: an updated review. Ann Med. 2014;46(6):372-83.

35. Kaur H, Moreau R. Curcumin represses mTORC1 signaling in Caco-2 cells by a two-sided mechanism involving the loss of IRS-1 and activation of AMPK. Cellular Signalling. 2021;78:109842.

36. Santana-Martínez RA, Silva-Islas CA, Fernández-Orihuela $Y Y$, et al. The Therapeutic Effect of Curcumin in Quinolinic Acid-Induced Neurotoxicity in Rats is Associated with BDNF, ERK1/2, Nrf2, and Antioxidant Enzymes. Antioxidants (Basel). 2019;8(9).

37. Taverna S, Giallombardo M, Pucci M, et al. Curcumin inhibits in vitro and in vivo chronic myelogenous leukemia cells growth: a possible role for exosomal disposal of miR-21. Oncotarget. 2015;6(26):21918-33.

38. Sun J, Chen F, Braun C, et L. Role of curcumin in the management of pathological pain. Phytomedicine. 2018;48:129-40.

39. Dou H, Shen R, Tao J, Huang L, Shi H, Chen $\mathrm{H}$, Wang $Y$, Wang T. Curcumin Suppresses the Colon Cancer Proliferation by Inhibiting Wnt/ $\beta$-Catenin Pathways via miR-130a. Front Pharmacol. 2017;8:877.

40. Aggarwal BB, Sethi G, Ahn KS, ET AL. Targeting signal-transducer-and-activator-of-transcription-3 for prevention and therapy of cancer: modern target but ancient solution. Ann N Y Acad Sci. 2006;1091:151-69.

41. Khan AQ, Ahmed El, Elareer $\mathrm{N}$, et al. Curcumin-Mediated Apoptotic Cell Death in Papillary Thyroid Cancer and Cancer Stem-Like Cells through Targeting of the JAK/STAT3 Signaling Pathway. Int J Mol Sci. 2020;21(2).

42. Balogun $E$, Hoque M, Gong P, et al. Curcumin activates the haem oxygenase-1 gene via regulation of $\mathrm{Nrf2}$ and the antioxidant-responsive element. Biochem J. 2003;371(Pt 3):887-95.

43. Magesh S, Chen Y, Hu L. Small molecule modulators of Keap1-Nrf2-ARE pathway as potential preventive and therapeutic agents. Med Res Rev. 2012;32(4):687-726.

44. Ren L, Zhan P, Wang Q, et al. Curcumin upregulates the Nrf2 system 
by repressing inflammatory signaling-mediated Keap1 expression in insulin-resistant conditions. Biochemical and Biophysical Research Communications. 2019;514(3):691-8.

45. Zia A, Farkhondeh T, Pourbagher-Shahri AM, Samarghandian S. The role of curcumin in aging and senescence: Molecular mechanisms. Biomedicine \& Pharmacotherapy. 2021;134:111119.

46. Sang $Q$, Liu $X$, Wang $L$, et al. Curcumin Protects an SH-SY5Y Cell Model of Parkinson's Disease Against Toxic Injury by Regulating HSP90. Cell Physiol Biochem. 2018;51(2):681-91.

47. Liu W, Zhai Y, Heng X, Che FY, Chen W, Sun D, Zhai G. Oral bioavailability of curcumin: problems and advancements. J Drug Target. 2016;24(8):694-702.

48. Metzler M, Pfeiffer E, Schulz SI, Dempe JS. Curcumin uptake and metabolism. Biofactors. 2013;39(1):14-20.

49. Hassaninasab A, Hashimoto Y, Tomita-Yokotani K, Kobayashi M. Discovery of the curcumin metabolic pathway involving a unique enzyme in an intestinal microorganism. Proc Natl Acad Sci USA. 2011;108(16):6615-20.

50. Sharma RA, McLelland HR, Hill KA, et al. Pharmacodynamic and pharmacokinetic study of oral Curcuma extract in patients with colorectal cancer. Clin Cancer Res. 2001;7(7):1894-900.

51. Sharma RA, Euden SA, Platton SL, et al. Phase I clinical trial of oral curcumin: biomarkers of systemic activity and compliance. Clin Cancer Res. 2004;10(20):6847-54.

52. Garcea G, Jones DJ, Singh R, et al. Detection of curcumin and its metabolites in hepatic tissue and portal blood of patients following oral administration. $\mathrm{Br} \mathrm{J}$ Cancer. 2004;90(5):1011-5.

53. Garcea G, Berry DP, Jones DJ, et al. Consumption of the putative chemopreventive agent curcumin by cancer patients: assessment of curcumin levels in the colorectum and their pharmacodynamic consequences. Cancer Epidemiol Biomarkers Prev. 2005;14(1):120-5.

54. Lao CD, Ruffin MTt, Normolle D, et al. Dose escalation of a curcuminoid formulation. BMC Complement Altern Med. 2006;6:10.

55. Vareed SK, Kakarala M, Ruffin MT, et al. Pharmacokinetics of curcumin conjugate metabolites in healthy human subjects. Cancer Epidemiol Biomarkers Prev. 2008;17(6):1411-7.

56. Asher GN, Xie Y, Moaddel R, et al. Randomized pharmacokinetic crossover study comparing 2 curcumin preparations in plasma and rectal tissue of healthy human volunteers. J Clin Pharmacol. 2017;57(2):185-93.

57. Klickovic U, Doberer D, Gouya G, et al. Human pharmacokinetics of high dose oral curcumin and its effect on heme oxygenase-1 expression in healthy male subjects. Biomed Res Int. 2014;2014:458592.

58. Ringman JM, Frautschy SA, Teng E, Begum AN, Bardens J, Beigi M, Gylys KH, Badmaev $V$, Heath DD, Apostolova LG, Porter V, Vanek Z, Marshall GA, Hellemann G, Sugar $C$, Masterman DL, Montine TJ, Cummings JL, Cole GM. Oral curcumin for Alzheimer's disease: tolerability and efficacy in a 24-week randomized, double blind, placebo-controlled study. Alzheimers Res Ther. 2012;4(5):43.

59. Goulart RA, Barbalho SM, Lima VM, et al. Effects of the Use of Curcumin on UIcerative Colitis and Crohn's Disease: A Systematic Review. J Med Food. 2020.

60. Saleem S, Khan R, Kazmi I, Afzal M. Medicinal Plants in the Treatment of Arthritis. In: Ozturk M, Hakeem KR, editors. Plant and Human Health, Volume 3: Pharmacology and Therapeutic Uses. Cham: Springer International Publishing; 2019;101-37.

61. Khaleghi M. New Arthritis Foundation Guidelines On CBD Use Could Be First Of Many More To Come. Altern Ther Health Med. 2020;26(S1):8-11. 
62. Paglia MDG, Silva MT, Lopes LC, et al. Use of corticoids and non-steroidal anti-inflammatories in the treatment of rheumatoid arthritis: Systematic review and network meta-analysis. PLoS One. 2021;16(4):e0248866.

63. Moore N, Duong M, Gulmez SE, Blin P, Droz C. Pharmacoepidemiology of non-steroidal anti-inflammatory drugs. Therapie. 2019;74(2):271-7.

64. Choudhary $M$, Kumar $V$, Malhotra $H$, Singh S. Medicinal plants with potential anti-arthritic activity. J Intercult Ethnopharmacol. 2015;4(2):147-79.

65. Patel SS, Acharya A, Ray RS, Agrawal R, Raghuwanshi R, Jain P. Cellular and molecular mechanisms of curcumin in prevention and treatment of disease. Crit Rev Food Sci Nutr. 2020;60(6):887-939.

66. Epstein J, Sanderson IR, Macdonald TT. Curcumin as a therapeutic agent: the evidence from in vitro, animal and human studies. Br J Nutr. 2010;103(11):1545-57.

67. Karimian MS, Pirro M, Majeed M, Sahebkar A. Curcumin as a natural regulator of monocyte chemoattractant protein-1. Cytokine \& Growth Factor Reviews. 2017;33:55-63.

68. Shehzad A, Rehman G, Lee YS. Curcumin in inflammatory diseases. Biofactors. 2013;39(1):69-77.

69. Zhou YY, Zhang TT, Wang $X F$, et al. Curcumin Modulates Macrophage Polarization Through the Inhibition of the Toll-Like Receptor 4 Expression and its Signaling Pathways. Cellular Physiology and Biochemistry. 2015;36(2):631-41.

70. Li X, Xu DQ, Sun DY, Zhang T, He X, Xiao DM. Curcumin ameliorates monosodium urate-induced gouty arthritis through Nod-like receptor 3 inflammasome mediation via inhibiting nuclear factor-kappa B signaling. Journal of Cellular Biochemistry. 2019;120(4):6718-28.

71. Chen B, Li H, Ou G, Ren L, Yang X, Zeng M. Curcumin attenuates MSU crystal-induced inflammation by inhibiting the degradation of IkappaBalpha and blocking mitochondrial damage. Arthritis Res Ther. 2019;21(1):193.

72. Zhang $Y$, Zeng Y. Curcumin reduces inflammation in knee osteoarthritis rats through blocking TLR4 /MyD88/NF-kappaB signal pathway. Drug Dev Res. 2019;80(3):353-9.

73. Feng $K$, Ge $Y$, Chen $Z$, et al. Curcumin Inhibits the PERK-elF2alpha-CHOP Pathway through Promoting SIRT1 Expression in Oxidative Stress-induced Rat Chondrocytes and Ameliorates Osteoarthritis Progression in a Rat Model. Oxid Med Cell Longev. 2019;2019:8574386.

74. Feng K, Chen Z, Pengcheng L, Zhang $S$, Wang $X$. Quercetin attenuates oxidative stress-induced apoptosis via SIRT1/ AMPK-mediated inhibition of ER stress in rat chondrocytes and prevents the progression of osteoarthritis in a rat model. J Cell Physiol. 2019;234(10):18192-205.

75. Dai Q, Zhou D, Xu L, Song X. Curcumin alleviates rheumatoid arthritis-induced inflammation and synovial hyperplasia by targeting mTOR pathway in rats. Drug Des Devel Ther. 2018;12:4095-105.

76. Zhang G, Cao J, Yang E, et al. Curcumin improves age-related and surgically induced osteoarthritis by promoting autophagy in mice. Biosci Rep. 2018;38(4):BSR20171691.

77. Chen $T$, Zhou R, Chen $Y$, et al. Curcumin ameliorates IL-1 beta-induced apoptosis by activating autophagy and inhibiting the NF-kappaB signaling pathway in rat primary articular chondrocytes. Cell Biol Int. 2020:976-88.

78. Henrotin $Y$, Malaise $M$, Wittoek $R$, et al Bio-optimized Curcuma longa extract is efficient on knee osteoarthritis pain: a double-blind multicenter randomized placebo controlled three-arm study. Arthritis Res Ther. 2019;21(1):179.

79. Nakagawa Y, Mukai S, Yamada S, Murata $S$, Yabumoto $H$, Maeda T, Akamatsu S. The Efficacy and Safety of Highly-Bio- 
available Curcumin for Treating Knee Osteoarthritis: A 6-Month Open-Labeled Prospective Study. Clin Med Insights Arthritis Musculoskelet Disord. 2020;13:1179544120948471.

80. Shep D, Khanwelkar C, Gade P, Karad S. Safety and efficacy of curcumin versus diclofenac in knee osteoarthritis: a randomized open-label parallel-arm study. Trials. 2019;20(1):214.

81. Fallahi F, Borran S, Ashrafizadeh M, et al. Curcumin and inflammatory bowel diseases: From in vitro studies to clinical trials. Mol Immunol. 2021;130:20-30.

82. Burge K, Gunasekaran A, Eckert J, Chaaban H. Curcumin and Intestinal Inflammatory Diseases: Molecular Mechanisms of Protection. Int $\mathrm{J}$ Mol Sci. 2019;20(8).

83. Holleran G, Scaldaferri F, Gasbarrini A, Curro D. Herbal medicinal products for inflammatory bowel disease: A focus on those assessed in double-blind randomised controlled trials. Phytother Res. 2020;34(1):77-93

84. Hanai $\mathrm{H}$, lida $\mathrm{T}$, Takeuchi $\mathrm{K}$, et al. Curcumin maintenance therapy for ulcerative colitis: randomized, multicenter, double-blind, placebo-controlled trial. Clin Gastroenterol Hepatol. 2006;4(12):1502-6.

85. Mazieiro R, Frizon RR, Barbalho SM, Goulart RA. Is Curcumin a Possibility to Treat Inflammatory Bowel Diseases? J Med Food. 2018;21(11):1077-85.

86. Eke-Okoro UJ, Raffa RB, Pergolizzi JV, et al. Curcumin in turmeric: Basic and clinical evidence for a potential role in analgesia. J Clin Pharm Ther. 2018;43(4):460-6.

87. Menghini L, Genovese S, Epifano F, Tirillini B, Ferrante C, Leporini L. Antiproliferative, Protective and Antioxidant Effects of Artichoke, Dandelion, Turmeric and Rosemary Extracts and Their Formulation. International Journal of Immunopathology and Pharmacology. 2010;23(2):601-10.
88. Sannia A. Phytotherapy with a mixture of dry extracts with hepato-protective effects containing artichoke leaves in the management of functional dyspepsia symptoms. Minerva Gastroenterol Dietol. 2010;56(2):93-9.

89. Neha S, Ranvir GD, Jangade CR. Analgesic and antipyretic activities of Curcuma longa rhizome extracts in Wistar Rats. Vet World. 2009;2:304-6.

90. Mohan M, Hussain MA, Khan FA, Anindya R. Symmetrical and un-symmetrical curcumin analogues as selective COX-1 and COX-2 inhibitor. European Journal of Pharmaceutical Sciences. 2021;160:105743.

91. Wang $M$, Kou J, Wang C, Yu X, Xie X, Pang $X$. Curcumin inhibits APOE4-induced injury by activating peroxisome proliferator-activated receptor-gamma (PPARgamma) in SH-SY5Y cells. Iran J Basic Med Sci. 2020;23(12):1576-83.

92. Jiang $P$, Jiang $Q$, Yan $Y$, Hou Z, Luo D. Propofol ameliorates neuropathic pain and neuroinflammation through PPAR $\gamma$ up-regulation to block Wnt/ $\beta$-catenin pathway. Neurol, Res. 2021;43(1):71-7.

93. Zhang $L, M a Z, W u Z$, Jin $M, A n L$, Xue F. Curcumin Improves Chronic Pain Induced Depression Through Regulating Serum Metabolomics in a Rat Model of Trigeminal Neuralgia. J Pain Res. 2020;13:3479-92.

94. Abd-Rabo MM, Georgy GS, Saied NM, Hassan WA. Involvement of the serotonergic system and neuroplasticity in the antidepressant effect of curcumin in ovariectomized rats: Comparison with oestradiol and fluoxetine. Phytother Res. 2019;33(2):387-96.

95. Choi GY, Kim HB, Hwang ES, et al. Curcumin Alters Neural Plasticity and Viability of Intact Hippocampal Circuits and Attenuates Behavioral Despair and COX-2 Expression in Chronically Stressed Rats. Mediators Inflamm. 2017;2017:6280925. 
96. Lopez-Alvarez VM, Puigdomenech $M$, Navarro X, Cobianchi S. Monoaminergic descending pathways contribute to modulation of neuropathic pain by increasing-intensity treadmill exercise after peripheral nerve injury. Exp Neurol. 2018;299(Pt A):42-55.

97. Matias JN, Achete G, Campanari G, et al. A systematic review of the antidepressant effects of curcumin: Beyond monoamines theory. Aust N Z J Psychiatry. 2021:4867421998795.

98. Mittal N, Joshi R, Hota D, Chakrabarti A. Evaluation of antihyperalgesic effect of curcumin on formalin-induced orofacial pain in rat. Phytother Res. 2009;23(4):507-12.

99. Seo HJ, Wang SM, Han C, Lee SJ, Patkar AA, Masand PS, Pae CU. Curcumin as a putative antidepressant. Expert Review of Neurotherapeutics. 2015;15(3):269-80.

100. Limcharoen T, Muangnoi C, Dasuni Wasana PW, Hasriadi VORPTPlaa, anti-inflammatory response achieved through potential prodrug of curcumin coldiammonp. Improved antiallodynic, antihyperalgesic and anti-inflammatory response achieved through potential prodrug of curcumin, curcumin diethyl diglutarate in a mouse model of neuropathic pain. 2021;899:174008.

101. Saffarpour S, Janzadeh A, Rahimi B, Ramezani F, Nasirinezhad F. Chronic nanocurcumin treatment ameliorates pain-related behavior, improves spatial memory, and reduces hippocampal levels of IL-1beta and TNFalpha in the chronic constriction injury model of neuropathic pain. Psychopharmacology (Berl). 2021;238(3):877-86.

102. Park H, Lee JH, Sim JH, Park J, Choi SS, Leem JG. Effects of Curcumin Treatment in a Diabetic Neuropathic Pain Model of Rats: Involvement of c-Jun N-Terminal Kinase Located in the Astrocytes and Neurons of the Dorsal Root Gan- glion. Pain research \& management. 2021;2021:8787231.

103. Chen $Z$, Sun D, Bi X, Zeng $X$, et al. Pharmacokinetic based study on "lagged stimulation" of Curcumae Longae Rhizoma Piper nigrum couplet in their main active components' metabolism using UPLCMS-MS. Phytomedicine. 2017;27:15-22.

104. Shen L, Liu CC, An CY, Ji HF. How does curcumin work with poor bioavailability? Clues from experimental and theoretical studies. Sci Rep. 2016;6:20872.

105. Hashemzadeh K, Davoudian N, Jaafari MR, Mirfeizi Z. The Effect of Nanocurcumin in Improvement of Knee Osteoarthritis: A Randomized Clinical Trial. Curr Rheumatol Rev. 2020;16(2):158-64.

106. Raman P, Pitty R, Krithika CL, Anand SPN, Subramani GP. Topical Curcumin and Triamcinolone Acetonide in Recurrent Minor Aphthous Ulcers: A Pilot Trial. J Contemp Dent Pract. 2020;21(8):884-90.

107. Anderson AS, Key TJ, Norat T, et al. European Code against Cancer 4th Edition: Obesity, body fatness and cancer. Cancer Epidemiol. 2015;39 Suppl 1:S34-45.

108. Collaborators GBDO, Afshin A, Forouzanfar $\mathrm{MH}$, et al. Health Effects of Overweight and Obesity in 195 Countries over 25 Years. N Engl J Med. 2017;377(1):13-27.

109. Bradford PG. Curcumin and obesity. Biofactors. 2013;39(1):78-87.

110. Zhao Y, Chen B, Shen J, et al. The Beneficial Effects of Quercetin, Curcumin, and Resveratrol in Obesity. Oxid Med Cell Longev. 2017;2017:1459497.

111. Akbari $M$, Lankarani $K B$, Tabrizi $R$, et al. The Effects of Curcumin on Weight Loss Among Patients With Metabolic Syndrome and Related Disorders: A Systematic Review and Meta-Analysis of Randomized Controlled Trials. Front Pharmacol. 2019;10:649.

112. Panzhinskiy E, Bashir R, Bagchi D, Nair S. Effect of Curcumin and alpha-Lipoic Acid 
in Attenuating Weight Gain and Adiposity. J Am Coll Nutr. 2019;38(6):493-8.

113. Pan $Y$, Zhao D, Yu N, et al. Curcumin improves glycolipid metabolism through regulating peroxisome proliferator activated receptor gamma signalling pathway in high-fat diet-induced obese mice and 3T3-L1 adipocytes. R Soc Open Sci. 2017;4(11):170917.

114. Koboziev I, Scoggin S, Gong X, et al. Effects of Curcumin in a Mouse Model of Very High Fat Diet-Induced Obesity Biomolecules. 2020;10(10):1368.

115. Zhao D, Pan $Y, Y u$ N, et al. Curcumin improves adipocytes browning and mitochondrial function in 3T3-L1 cells and obese rodent model. R Soc Open Sci. 2021;8:200974.

116. Sarker $M R$, Franks $S$, Sumien $N$, Thangthaeng N, Filipetto F, Forster M. Curcumin Mimics the Neurocognitive and Anti-Inflammatory Effects of Caloric Restriction in a Mouse Model of Midlife Obesity. PLoS One. 2015;10(10):e0140431.

117. Varì $R$, Scazzocchio $B$, Silenzi $A$, Giovannini C, Masella R. Obesity-Associated Inflammation: Does Curcumin Exert a Beneficial Role? Nutrients. 2021;13(3):1021.

118. Wu LY, Chen CW, Chen LK, Chou HY, Chang $\mathrm{CL}$, Juan CC. Curcumin Attenuates Adipogenesis by Inducing Preadipocyte Apoptosis and Inhibiting Adipocyte Differentiation. Nutrients. 2019;11(10):2307.

119. Wang $T$, Yan $R, X u X$, et al. Curcumin represses adipogenic differentiation of human bone marrow mesenchymal stem cells via inhibiting kruppel-like factor 15 expression. Acta Histochem. 2019;121(2):253-9.

120. Cheng L, Wang J, Dai H, et al. Brown and beige adipose tissue: a novel therapeutic strategy for obesity and type 2 diabetes mellitus. Adipocyte. 2021;10(1):48-65.

121. Song Z, Revelo X, Shao W, et al. Dietary Curcumin Intervention Targets Mouse White Adipose Tissue Inflammation and Brown Adipose Tissue UCP1
Expression. Obesity (Silver Spring). 2018;26(3):547-58.

122. Dei Cas M, Ghidoni R. Dietary Curcumin: Correlation between Bioavailability and Health Potential. Nutrients. 2019;11(9):2147.

123. Nishikawa $S$, Kamiya $M$, Aoyama $H$, et al. Highly Dispersible and Bioavailable Curcumin but not Native Curcumin Induces Brown-Like Adipocyte Formation in Mice. Mol Nutr Food Res. 2018;62(5).

124. Babu PS, Srinivasan K. Influence of dietary curcumin and cholesterol on the progression of experimentally induced diabetes in albino rat. Mol Cell Biochem. 1995;152(1):13-21.

125. Babu PS, Srinivasan K. Hypolipidemic action of curcumin, the active principle of turmeric (Curcuma longa) in streptozotocin induced diabetic rats. Mol Cell Biochem. 1997;166(1-2):169-75.

126. Ferns GA, Mohammadi A, Sahebkar A, et al. Effects of supplementation with curcuminoids on dyslipidemia in obese patients: A randomized crossover trial. Phytother Res. 2013;27:374-9.

127. Garg ML, Ferguson JJA, Stojanovski E, MacDonald-Wicks L. Curcumin potentiates cholesterol-lowering effects of phytosterols in hypercholesterolaemic individuals. A randomised controlled trial Metabolism. 2018;82:22-35.

128. Gilani AH, Amin F, Islam N, Anila N. Clinical efficacy of the co-administration of turmeric and black seeds (Kalongi) in metabolic syndrome-a double blind randomized controlled trial-TAK-MetS trial. Complement Ther Med. 2015;23:165-74.

129. Kazemi OR, Rahimi HR, Mohammadpour $\mathrm{AH}$, et al. The effect of nano-curcumin on $\mathrm{HbA} 1 \mathrm{c}$, fasting blood glucose, and lipid profile in diabetic subjects: A randomized clinical trial. Avicenna J Phytomed. 2016;6:567-77.

130. Maithili KSN, Sridhar MG, Swaminathan RP, Sripradha R. Efficacy of turmeric as adjuvant therapy in type 2 di- 
abetic patients. Indian J Clin Biochem. 2015;30:180-6.

131. Panahi $Y$, Khalili N, Hosseini MS, Abbasinazari M, Sahebkar A. Lipid-modifying effects of adjunctive therapy with curcuminoids-piperine combination in patients with metabolic syndrome: results of a randomized controlled trial. Complement Ther Med. 2014;22(5):851-7.

132. Panahi $Y$, Khalili N, Sahebi E, Namazi $S$, Reiner Z, Majeed M, Sahebkar A. Curcuminoids modify lipid profile in type 2 diabetes mellitus: A randomized controlled trial. Complement Ther Med. 2017;33:1-5.

133. Panahi $Y$, Kianpour $P$, Mohtashami $R$, et al. Curcumin Lowers Serum Lipids and Uric Acid in Subjects With Nonalcoholic Fatty Liver Disease: A Randomized Controlled Trial. J Cardiovasc Pharmacol. 2016;68(3):223-9.

134. Ueng K, Yang YS, Su YF, Yang HW, Lee $\mathrm{YH}$, Chou JI. Lipid-lowering effects of curcumin in patients with metabolic syndrome: A randomized, double-blind, placebo-controlled trial. Phytother Res. 2014;28:1770-7.

135. Xia ZH, Chen WB, Shi L, et al. The Underlying Mechanisms of Curcumin Inhibition of Hyperglycemia and Hyperlipidemia in Rats Fed a High-Fat Diet Combined With STZ Treatment. Molecules. 2020;25(2).

136. Ganjali S, Blesso CN, Banach M, Pirro M, Majeed M, Sahebkar A. Effects of curcumin on HDL functionality. Pharmacol Res. 2017;119:208-18.

137. Panahi $Y$, Ahmadi $Y$, Teymouri M, Johnston T, Sahebkar A. Curcumin as a potential candidate for treating hyperlipidemia: A review of cellular and metabolic mechanisms J Cell Physiol 2018;233(1):141-52.

138. Yuan F, Dong H, Gong J, et al. A Systematic Review and Meta-analysis of Randomized Controlled Trials on the Effects of Turmeric and Curcuminoids on Blood
Lipids in Adults with Metabolic Diseases. Adv Nutr. 2019;10(5):791-802.

139. Silva $C B$, Fassini $P G$, Ramalho $L N Z$, da Conceição EC, Zordan A, Carlos D, Suen VMM. Curcumin Supplementation in high-fat-fed C57BL/6 mice: no beneficial effect on lipid and glucose profile or prevention of weight gain. Eur J Nutr. 2020;59(1):93-102.

140. Zingg JM, Hasan ST, Meydani M. Molecular mechanisms of hypolipidemic effects of curcumin. Biofactors. 2013;39(1):101-21.

141. Zingg JM, Hasan ST, Nakagawa $K$, et al. Modulation of CAMP levels by high-fat diet and curcumin and regulatory effects on CD36/FAT scavenger receptor/fatty acids transporter gene expression. Biofactors. 2017;43(1):42-53.

142. Maithilikarpagaselvi N, Sridhar MG, Swaminathan RP, Sripradha R, Badhe B. Curcumin inhibits hyperlipidemia and hepatic fat accumulation in high-fructose-fed male Wistar rats. Pharm Biol. 2016;54(12):2857-63.

143. Anand $P$, Kunnumakkara $A B$, Newman RA, Aggarwal BB. Bioavailability of curcumin: problems and promises. Mol Pharm. 2007;4(6):807-18.

144. Jurenka JS. Anti-inflammatory properties of curcumin, a major constituent of Curcuma longa: a review of preclinical and clinical research. Altern Med Rev. 2009;14(2):141-53.

145. Shamsi-Goushki A, Mortazavi Z, Mirshekar MA, et al. Comparative Effects of Curcumin versus Nano-Curcumin on Insulin Resistance, Serum Levels of Apelin and Lipid Profile in Type 2 Diabetic Rats. Diabetes Metab Syndr Obes. 2020;13:2337-46.

146. WHO. Available from: www.who.int/ news-room/fact-sheets/detail/diabetes.

147. Den Hartogh DJ, Gabriel A, Tsiani E. Antidiabetic Properties of Curcumin II: Evidence from In Vivo Studies. Nutrients. 2019;12(1):58. 
148. Canistro D, Vivarelli F, Cirillo $S$, et al. Efficacy of a new delivery system based on solid lipid microparticles for the oral administration of the non-conventional antioxidant IAC on a diabetes mouse model. J Endocrinol Invest. 2018;41(10):1227-36.

149. Zheng Y, Ley SH, Hu FB. Global aetiology and epidemiology of type 2 diabetes mellitus and its complications. Nat Rev Endocrinol. 2018;14(2):88-98.

150. Marrelli M, Statti G, Conforti F. A Review of Biologically Active Natural Products from Mediterranean Wild Edible Plants: Benefits in the Treatment of Obesity and Its Related Disorders. Molecules. 2020;25(3):649.

151. Pivari F, Mingione A, Brasacchio C, Soldati L. Curcumin and Type 2 Diabetes Mellitus: Prevention and Treatment. Nutrients. 2019;11(8):1837.

152. Gutierres VO, Assis RP, Arcaro CA, et al. Curcumin improves the effect of a reduced insulin dose on glycemic control and oxidative stress in streptozotocin-diabetic rats. Phytother Res. 2019;33(4):976-88.

153. Xie Z, Wu B, Shen G, Li X, Wu Q. Curcumin alleviates liver oxidative stress in type 1 diabetic rats. Mol Med Rep. 2018;17(1):103-8.

154. Ibrahim ZS, Alkafafy ME, Ahmed MM, Soliman MM. Renoprotective effect of curcumin against the combined oxidative stress of diabetes and nicotine in rats. Mol Med Rep. 2016;13(4):3017-26.

155. Costa MC, Lima TFO, Arcaro CA, Inacio MD, Batista-Duharte A, Carlos IZ, Spolidorio LC, Assis RP, Brunetti IL, Baviera AM. Trigonelline and curcumin alone, but not in combination, counteract oxidative stress and inflammation and increase glycation product detoxification in the liver and kidney of mice with highfat diet-induced obesity. J Nutr Biochem. 2020;76:108303.

156. Ganugula R, Arora M, Jaisamut $P$, Wiwattanapatapee $R$, Jorgensen HG, Venkatpurwar VP, Zhou B, Rodrigues Hoffmann
A, Basu R, Guo S, Majeti N. Nano-curcumin safely prevents streptozotocin-induced inflammation and apoptosis in pancreatic beta cells for effective management of Type 1 diabetes mellitus. $\mathrm{Br}$ J Pharmacol. 2017;174(13):2074-84.

157. Solinas G, Karin M. JNK1 and IKKbeta: molecular links between obesity and metabolic dysfunction. FASEB J. 2010;24(8):2596-611.

158. Ran Z, Zhang Y, Wen X, Ma J. Curcumin inhibits high glucoseinduced inflammatory injury in human retinal pigment epithelial cells through the ROSPI3K/AKT/ mTOR signaling pathway. Mol Med Rep. 2019;19(2):1024-31.

159. Donath MY, Dinarello CA, Mandrup-Poulsen T. Targeting innate immune mediators in type 1 and type 2 diabetes. Nat Rev Immunol. 2019;19(12):734-46.

160. Rogero MM, Calder PC. Obesity, Inflammation, Toll-Like Receptor 4 and Fatty Acids. Nutrients. 2018;10(4):432.

161. Nikolic I, Leiva M, Sabio G. The role of stress kinases in metabolic disease. Nat Rev Endocrinol. 2020;16(12):697-716.

162. Feng J, Lu S, Ou B, et al. The Role of JNk Signaling Pathway in Obesity-Driven Insulin Resistance. Diabetes Metab Syndr Obes. 2020;13:1399-406.

163. Liju VB, Jeena K, Kuttan R. Acute and subchronic toxicity as well as mutagenic evaluation of essential oil from turmeric (Curcuma longa L). Food Chem Toxicol. 2013;53:52-61.

164. Lu X, Wu F, Jiang M, Sun X, Tian G. Curcumin ameliorates gestational diabetes in mice partly through activating AMPK. Pharm Biol. 2019;57(1):250-4.

165. Bahramsoltani $\mathrm{R}$, Rahimi $\mathrm{R}$, Farzaei $\mathrm{MH}$. Pharmacokinetic interactions of curcuminoids with conventional drugs: A review. J Ethnopharmacol. 2017;209:1-12.

166. Bonamassa B, Canistro D, Sapone A, Vivarelli $F$, Vornoli $A$, Longo $V$, Paolini $M$. Harmful effects behind the daily supplementation of a fixed vegetarian blend 
in the rat model. Food Chem Toxicol. 2016;97:367-74.

167. Canistro D, Vivarelli F, Cirillo S, Costa G, Andreotti C, Paolini M. Comparison between in toto peach (Prunus persica L. Batsch) supplementation and its polyphenolic extract on rat liver xenobiotic metabolizing enzymes Food Chem Toxicol. 2016;97:385-94.

168. Hadi A, Pourmasoumi M, Ghaedi E, Sahebkar A. The effect of Curcumin/Turmeric on blood pressure modulation: A systematic review and meta-analysis. Pharmacol Res. 2019;150:104505.

169. Tubsakul A, Sangartit W, Pakdeechote P, Kukongviriyapan V, Apaijit K, Kukongviriyapan U. Curcumin Mitigates Hypertension, Endothelial Dysfunction and Oxidative Stress in Rats with Chronic Exposure to Lead and Cadmium. Tohoku J Exp Med. 2021;253(1):69-76.

170. du Preez R, Pahl J, Arora M, Ravi Kumar MNV, Brown L, Panchal SK. LowDose Curcumin Nanoparticles Normalise Blood Pressure in Male Wistar Rats with Diet-Induced Metabolic Syndrome. Nutrients. 2019;11(7).

171. Greish SM, Abdel-Hady Z, Mohammed SS, et al. Protective potential of curcumin in L-NAME-induced hypertensive rat model: AT1R, mitochondrial DNA synergy. Int J Physiol Pathophysiol Pharmacol. 2020;12(5):134-46.

172. Forstermann U, Munzel T. Endothelial nitric oxide synthase in vascular disease: from marvel to menace. Circulation. 2006;113(13):1708-14.

173. Tapia E, Soto V, Ortiz-Vega KM, et al. Curcumin induces Nrf2 nuclear translocation and prevents glomerular hypertension, hyperfiltration, oxidant stress, and the decrease in antioxidant enzymes in 5/6 nephrectomized rats. Oxid Med Cell Longev. 2012;2012:269039.

174. Yao Y, Wang W, Li M, Ren H, Chen C, Wang J, Wang WE, Yang J, Zeng C. Curcumin Exerts its Anti-hypertensive Effect by Down-regulating the AT1 Receptor in Vascular Smooth Muscle Cells. Sci Rep. 2016;6:25579.

175. Kim HR, Kim WK, Ha AW. Effects of Phytochemicals on Blood Pressure and Neuroprotection Mediated Via Brain Renin-Angiotensin System. Nutrients. 2019;11(11).

176. Ma Z, Wang N, He H, Tang X. Pharmaceutical strategies of improving oral systemic bioavailability of curcumin for clinical application. J Control Release. 2019;316:359-80.

177. Czyzynska-Cichon I, Janik-Hazuka M, Szafraniec-Szczesny J, Jasinski K, Weglarz WP, Zapotoczny S, Chlopicki S. Low Dose Curcumin Administered in Hyaluronic Acid-Based Nanocapsules Induces Hypotensive Effect in Hypertensive Rats. Int J Nanomedicine. 2021;16:1377-90.

178. Lan $C$, Chen $X$, Zhang $Y$, et al. Curcumin prevents strokes in stroke-prone spontaneously hypertensive rats by improving vascular endothelial function. BMC Cardiovasc Disord. 2018;18(1):43.

179. Konukoglu D, Uzun H. Endothelial Dysfunction and Hypertension. Adv Exp Med Biol. 2017;956:511-40.

180. Takeda Y, Matoba K, Sekiguchi K, et al. Endothelial Dysfunction in Diabetes. Biomedicines. 2020;8(7).

181. Felmeden DC, Blann AD, Lip GY. Angiogenesis: basic pathophysiology and implications for disease. European heart journal. 2003;24(7):586-603.

182. Ungvari Z, Tarantini S, Kiss Tet al. Endothelial dysfunction and angiogenesis impairment in the ageing vasculature. Nat Rev Cardiol. 2018;15(9):555-65.

183. Karimian MS, Pirro $M$, Johnston TP, Majeed M, Sahebkar A. Curcumin and Endothelial Function: Evidence and Mechanisms of Protective Effects. Curr Pharm Des. 2017;23(17):2462-73.

184. Campbell MS, Fleenor BS. The emerging role of curcumin for improving vascular 
dysfunction: A review. Crit Rev Food Sci Nutr. 2018;58(16):2790-9.

185. Pal S, Bhattacharjee A, Ali A, Mandal NC, Mandal SC, Pal M. Chronic inflammation and cancer: potential chemoprevention through nuclear factor kappa B and p53 mutual antagonism. Journal of inflammation (London, England). 2014;11:23.

186. Chen D, Weng L, Chen C, et al. Inflammation and dysfunction in human aortic endothelial cells associated with poly-l-lactic acid degradation in vitro are alleviated by curcumin. Journal of biomedical materials research Part $A$. 2019;107(12):2756-63.

187. Lu Q, Ye F, Yang $X$, et al. Accelerated Recovery of Endothelium Function after Stent Implantation with the Use of a Novel Systemic Nanoparticle Curcumin. Biomed Res Int. 2015;2015:291871.

188. Guo N, Chen F, Zhou J, et al. Curcumin Attenuates Rapamycin-induced Cell Injury of Vascular Endothelial Cells. J Cardiovasc Pharmacol. 2015;66(4):338-46.

189. Zhang Z, Li K. Curcumin attenuates high glucose-induced inflammatory injury through the reactive oxygen species-phosphoinositide 3-kinase/protein kinase B-nuclear factor-kappaB signaling pathway in rat thoracic aorta endothelial cells. J Diabetes Investig. 2018;9(4):731-40.

190. Li X, Xiao H, Lin C, et al. Synergistic effects of liposomes encapsulating atorvastatin calcium and curcumin and targeting dysfunctional endothelial cells in reducing atherosclerosis. Int J Nanomedicine. 2019;14:649-65.

191. Ashrafizadeh M, Ahmadi Z, Mohammadinejad R, Farkhondeh T, Samarghandian S. Curcumin Activates the Nrf2 Pathway and Induces Cellular Protection Against Oxidative Injury. Curr Mol Med. 2020;20(2):116-33.

192. Tebay LE, Robertson H, Durant ST, et al. Mechanisms of activation of the transcription factor Nrf2 by redox stressors, nutrient cues, and energy status and the pathways through which it attenuates degenerative disease. Free Radic Biol Med. 2015;88(Pt B):108-46.

193. Speciale A, Chirafisi J, Saija A, Cimino F. Nutritional antioxidants and adaptive cell responses: an update. Curr Mol Med. 2011;11(9):770-89.

194. Ooi BK, Chan KG, Goh BH, Yap WH. The Role of Natural Products in Targeting Cardiovascular Diseases via Nrf2 Pathway: Novel Molecular Mechanisms and Therapeutic Approaches. Front Pharmacol. 2018;9:1308.

195. Kloska D, Kopacz A, Piechota-Polanczyk A, et al. Nrf2 in aging - Focus on the cardiovascular system. Vascular pharmacology. 2019;112:42-53.

196. Speciale A, Anwar S, Canali R, Chirafisi J, Saija A, Virgili F, Cimino F. Cyanidin-3-O-glucoside counters the response to TNF-alpha of endothelial cells by activating Nrf2 pathway. Mol Nutr Food Res. 2013;57(11):1979-87.

197. Wardyn JD, Ponsford AH, Sanderson CM. Dissecting molecular cross-talk between Nrf2 and NF-kappaB response pathways. Biochem Soc Trans. 2015;43(4):621-6.

198. Daverey A, Agrawal SK. Curcumin Protects against White Matter Injury through NF-kappaB and Nrf2 Cross Talk. J Neurotrauma. 2020;37(10):1255-65.

199. Ouyang J, Li R, Shi H, Zhong J. Curcumin Protects Human Umbilical Vein Endothelial Cells against $\mathrm{H}(2) \mathrm{O}(2)$-Induced Cell Injury. Pain research \& management. 2019;2019:3173149.

200. Li PC, Chen SC, Hsueh YJ, et al. Gelatin scaffold with multifunctional curcumin-loaded lipid-PLGA hybrid microparticles for regenerating corneal endothelium. Materials science \& engineering $C$, Materials for biological applications. 2021;120:111753.

201. Wang TY, Chen JX. Effects of Curcumin on Vessel Formation Insight into the Pro- and Antiangiogenesis of Curcumin. 
Evid Based Complement Alternat Med. 2019;2019:1390795.

202. Shakeri A, Ward N, Panahi Y, Sahebkar A. Anti-Angiogenic Activity of Curcumin in Cancer Therapy: A Narrative Review. Curr Vasc Pharmacol. 2019;17(3):262-9.

203. Norooznezhad F, Rodriguez-Merchan EC, Asadi S, Norooznezhad AH. Curcumin: hopeful treatment of hemophilic arthropathy via inhibition of inflammation and angiogenesis. Expert Rev Hematol. 2020;13(1):5-11.

204. Kant V, Gopal A, Kumar D, et al. Curcumin-induced angiogenesis hastens wound healing in diabetic rats. The Journal of surgical research. 2015;193(2):978-88.

205. Fereydouni N, Darroudi M, Movaffagh J, et al. Curcumin nanofibers for the purpose of wound healing. J Cell Physiol. 2019;234(5):5537-54.

206. Alven S, Nqoro X, Aderibigbe BA. Polymer-Based Materials Loaded with Curcumin for Wound Healing Applications. Polymers (Basel). 2020;12(10).

207. Hamam F, Nasr A. Curcumin-Loaded Mesoporous Silica Particles as Wound-Healing Agent: An In vivo Study. Saudi J Med Med Sci. 2020;8(1):17-24.

208. Liao HT, Lai YT, Kuo CY, Chen JP. A bioactive multi-functional heparin-grafted aligned poly(lactide-co-glycolide)/curcumin nanofiber membrane to accelerate diabetic wound healing. Materials science \& engineering $C$, Materials for biological applications. 2021;120:111689.

209. Dehghani S, Dalirfardouei R, et al. Topical application of curcumin regulates the angiogenesis in diabetic-impaired cutaneous wound. Cell Biochem Funct. 2020;38(5):558-66.

210. Mohanty C, Pradhan J. A human epidermal growth factor-curcumin bandage bioconjugate loaded with mesenchymal stem cell for in vivo diabetic wound healing. Materials science \& engineering C, Materials for biological applications. 2020;111:110751.
211. Guo JW, Pu CM, Liu CY, Lo SL, Yen YH. Curcumin-Loaded Self-Microemulsifying Gel for Enhancing Wound Closure. Skin Pharmacol Physiol. 2020;33(6):300-8.

212. Lee HJ, Jeong $M, N a Y G, K i m ~ S J$, Lee HK, Cho CW. An EGF- and Curcumin-Co-Encapsulated Nanostructured Lipid Carrier Accelerates Chronic-Wound Healing in Diabetic Rats. Molecules. 2020;25(20).

213. Zhu LN, Mei X, Zhang ZG, Xie YP, Lang F. Curcumin intervention for cognitive function in different types of people: A systematic review and meta-analysis. Phytother Res. 2019;33(3):524-33.

214. Wang Z, Zhang Q, Huang $H$, Liu Z. The efficacy and acceptability of curcumin for the treatment of depression or depressive symptoms: A systematic review and meta-analysis. J Affect Disord. 2021;282:242-51.

215. Ramaholimihaso T, Bouazzaoui F, Kaladjian A. Curcumin in Depression: Potential Mechanisms of Action and Current Evidence-A Narrative Review. Front Psychiatry. 2020;11:572533.

216. Yi YH, Li J, Chen WA. Curcumin evokes antidepressant-like effects in mice by regulating miR-124/brain derived neurotrophic factor. Tropical Journal of Pharmaceutical Research. 2019;18(3):603-9.

217. de Gomes MG, Teixeira FEG, de Carvalho FB, et al. Curcumin-loaded lipid-core nanocapsules attenuates the immune challenge LPS-induced in rats: Neuroinflammatory and behavioral response in sickness behavior. Journal of Neuroimmunology. 2020;345.

218. Liao DH, Lv CF, Cao LZ, et al. Curcumin Attenuates Chronic Unpredictable Mild Stress-Induced Depressive-Like Behaviors via Restoring Changes in Oxidative Stress and the Activation of Nrf2 Signaling Pathway in Rats. Oxidative Medicine and Cellular Longevity. 2020;2020.

219. Marques JGD, Antunes FTT, Brum LFD, et al. Adaptogenic effects of curcumin 
on depression induced by moderate and unpredictable chronic stress in mice. Behavioural Brain Research. 2021;399.

220. Madiha S, Haider S. Curcumin restores rotenone induced depressive-like symptoms in animal model of neurotoxicity: assessment by social interaction test and sucrose preference test. Metab Brain Dis. 2019;34(1):297-308.

221. Mohammad Abu-Taweel G, Al-Fifi Z. Protective effects of curcumin towards anxiety and depression-like behaviors induced mercury chloride. Saudi J Biol Sci. 2021;28(1):125-34.

222. Tang M, Taghibiglou C. The Mechanisms of Action of Curcumin in Alzheimer's Disease. J Alzheimers Dis. 2017; 58(4):1003-16.

223. Alarcón-Espósito J, Mallea M, Rodríguez-Lavado J. From hybrids to new scaffolds: the latest medicinal chemistry goals in multi-target directed ligands for Alzheimer's disease. Current neuropharmacology. 2020.

224. Chainoglou E, Hadjipavlou-Litina D. Curcumin in health and diseases: Alzheimer's disease and curcumin analogues, derivatives, and hybrids. International Journal of Molecular Sciences. 2020;21(6).

225. Martin TD, Malagodi AJ, Chi EY, Evans DG. Computational Study of the Driving Forces and Dynamics of Curcumin Binding to Amyloid-beta Protofibrils. Journal of Physical Chemistry B. 2019;123(3):551-60.

226. Fukutomi R, Ohishi T, Koyama $Y$, Pervin M, Nakamura $Y$, Isemura M. Beneficial Effects of Epigallocatechin-3-O-Gallate, Chlorogenic Acid, Resveratrol, and Curcumin on Neurodegenerative Diseases. Molecules. 2021;26(2).

227. Yang $Y$, Zhang L. The effects of caloric restriction and its mimetics in Alzheimer's disease through autophagy pathways. Food \& function. 2020;11(2):1211-24.

228. Abdullah A, Mohd Murshid N, Makpol S. Antioxidant Modulation of mTOR and
Sirtuin Pathways in Age-Related Neurodegenerative Diseases. Molecular Neurobiology. 2020;57(12):5193-207.

229. Xu C, Xiao Z, Wu H, et al. BDMC protects $A D$ in vitro via AMPK and SIRT1. Translational Neuroscience. 2020;11(1):319-27.

230. Malampati S, Song JX, Tong BCK, et al. Targeting aggrephagy for the treatment of Alzheimer's disease. Cells. 2020;9(2).

231. Liang J, Zhou FL, Xiong XM, et al. Enhancing the retrograde axonal transport by curcumin promotes autophagic flux in N2a/APP695swe cells. Aging-Us. 2019;11(17):7036-50.

232. Huang $P$, Zheng $N$, Zhou HB, Huang J. Curcumin inhibits BACE1 expression through the interaction between ER $\beta$ and $\mathrm{NFKB}$ signaling pathway in SH-SY5Y cells. Mol Cell Biochem. 2020;463(1-2):161-73.

233. Kushwaha $P$, Singh $V$, Somvanshi $P$, et al. Identification of new BACE1 inhibitors for treating Alzheimer's disease. Journal of Molecular Modeling. 2021;27(2).

234. Song HC, Chen Y, Chen Y, et al. GSK-3 $\beta$ inhibition by curcumin mitigates amyloidogenesis via TFEB activation and anti-oxidative activity in human neuroblastoma cells. Free Radical Research. 2020.

235. Bhat A, Mahalakshmi AM, Ray B, et al. Benefits of curcumin in brain disorders. Biofactors. 2019;45(5):666-89.

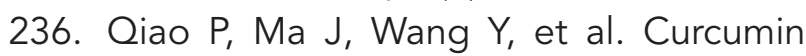
Prevents Neuroinflammation by Inducing Microglia to Transform into the M2-phenotype via CaMKK $\beta$-dependent Activation of the AMP-Activated Protein Kinase Signal Pathway. Current Alzheimer research. 2020;17(8):735-52.

237. Xu J, Zhou L, Weng Q, Xiao L, Li Q. Curcumin analogues attenuate $A \beta(25-35)$-induced oxidative stress in PC12 cells via Keap1/Nrf2/HO-1 signaling pathways. Chem Biol Interact. 2019;305:171-9.

238. Seo EJ, Fischer N, Efferth T. Phytochemicals as inhibitors of NF-kappaB for treatment of Alzheimer's disease. Pharmacol Res. 2018;129:262-73. 
239. Castejón-Vega B, Giampieri F, Alvarez-Suarez JM. Nutraceutical compounds targeting inflammasomes in human diseases. International Journal of Molecular Sciences. 2020;21(14):1-34.

240. Cakmak G, Kaplan DS, Yildirim C, Ulusal H, Tarakcioglu M, Ozturk ZA. Improvement of cognitive deficit by curcumin in scopolamineinduced Alzheimer's disease models. European Geriatric Medicine. 2020;11(SUPPL 1):S163.

241. Lin L, Li C, Zhang D, Yuan M, Chen $\mathrm{CH}$, Li M. Synergic Effects of Berberine and Curcumin on Improving Cognitive Function in an Alzheimer's Disease Mouse Model. Neurochemical Research. 2020;45(5):1130-41.

242. Porro C, Cianciulli A, Trotta T, Lofrumento DD, Panaro MA. Curcumin Regulates Anti-Inflammatory Responses by JAK/STAT/ SOCS Signaling Pathway in BV-2 Microglial Cells. Biology-Basel. 2019;8(3).

243. Cocorocchio M, Baldwin AJ, Stewart B, et al. Curcumin and derivatives function through protein phosphatase $2 \mathrm{~A}$ and presenilin orthologues in Dictyostelium discoideum. Dis Model Mech. 2018;11(1).

244. Iside C, Scafuro M, Nebbioso A, Altucci L. SIRT1 Activation by Natural Phytochemicals: An Overview. Frontiers in Pharmacology. 2020;11.

245. Gong J, Sun D. Study on the mechanism of curcumin to reduce the inflammatory response of temporal lobe in Alzheimer's disease by regulating miR-146a. Minerva medica. 2020.

246. Teter B, Morihara T, Lim GP, et al. Curcumin restores innate immune Alzheimer's disease risk gene expression to ameliorate Alzheimer pathogenesis. Neurobiology of Disease. 2019;127:432-48.

247. Wan $Y$, Liang $Y$, Liang $F$, et al. A Curcumin Analog Reduces Levels of the Alzheimer's Disease-Associated Amyloid- $\beta$ Protein by Modulating A $\beta$ PP Processing and Autophagy. J Alzheimers Dis. 2019;72(3):761-71.
248. Hannan MA, Dash $R$, Sohag AAM Haque MN, Moon IS. Neuroprotection Against Oxidative Stress: Phytochemicals Targeting TrkB Signaling and the Nrf2-ARE Antioxidant System. Frontiers in Molecular Neuroscience. 2020;13.

249. Das TK, Jana P, Chakrabarti SK, Abdul Hamid MRW. Curcumin Downregulates GSK3 and Cdk5 in Scopolamine-Induced Alzheimer's Disease Rats Abrogating $A \beta(40 / 42)$ and Tau Hyperphosphorylation. J Alzheimers Dis Rep. 2019;3(1):257-67.

250. Wang $H$, Sui $H J$, Zheng $Y$, Jiang $Y B$, et al L. Curcumin-primed exosomes potently ameliorate cognitive function in $A D$ mice by inhibiting hyperphosphorylation of the Tau protein through the AKT/GSK-3 beta pathway. Nanoscale. 2019;11(15):7481-96.

251. Arredondo SB, Valenzuela-Bezanilla D, Mardones MD, Varela-Nallar L. Role of Wnt Signaling in Adult Hippocampal Neurogenesis in Health and Disease. Frontiers in Cell and Developmental Biology. 2020;8.

252. Tiwari SK, Agarwal S, Seth B, et al. Curcumin-Loaded Nanoparticles Potently Induce Adult Neurogenesis and Reverse Cognitive Deficits in Alzheimer's Disease Model via Canonical Wnt/beta-Catenin Pathway (vol 8, pg 76, 2014). Acs Nano. 2019;13(6):7355-

253. Tripanichkul W, Jaroensuppaperch E. Curcumin protects nigrostriatal dopaminergic axons and increases BDNF immunoreactivity in the 6-OHDA-lesioned striatum of mice. Journal of the Medical Association of Thailand. 2019;102(7):5-11.

254. Shi LY, Zhang L, Li $H$, et al. Protective effects of curcumin on acrolein-induced neurotoxicity in HT22 mouse hippocampal cells. Pharmacol Rep. 2018;70(5):1040-6.

255. Heebkaew N, Rujanapun N, Kunhorm P, et al. Curcumin Induces Neural Differen- 
tiation of Human Pluripotent Embryonal Carcinoma Cells through the Activation of Autophagy. Biomed Research International. 2019;2019.

256. Li J, Han Y, Li M, Nie C. Curcumin Promotes Proliferation of Adult Neural Stem Cells and the Birth of Neurons in Alzheimer's Disease Mice via Notch Signaling Pathway. Cell Reprogram. 2019;21(3):152-61.

257. Maiti P, Bowers Z, Bourcier-Schultz A, Morse J, Dunbar GL. Preservation of dendritic spine morphology and postsynaptic signaling markers after treatment with solid lipid curcumin particles in the 5xFAD mouse model of Alzheimer's amyloidosis. Alzheimer's Research and Therapy. 2021;13(1).

258. Qian W, Li H, Pan N, Zhang C. Curcumin Treatment is Associated with Increased Expression of the N-Methyl-D-Aspartate Receptor (NMDAR) Subunit, NR2A, in a Rat PC12 Cell Line Model of Alzheimer's Disease Treated with the Acetyl Amyloid-beta Peptide, Abeta(25-35). Med Sci Monit. 2018;24:2693-9.

259. Pluta R, Ulamek-Koziol M, Czuczwar SJ. Neuroprotective and Neurological/Cognitive Enhancement Effects of Curcumin after Brain Ischemia Injury with Alzheimer's Disease Phenotype. Int J Mol Sci. 2018;19(12).

260. Das TK, Chakrabarti SK, Zulkipli IN, Abdul Hamid MRW. Curcumin Ameliorates the Impaired Insulin Signaling Involved in the Pathogenesis of Alzheimer's Disease in Rats. J Alzheimers Dis Rep. 2019;3(1):59-70.

261. Lu WT, Sun SQ, Li Y, et al. Curcumin Ameliorates Memory Deficits by Enhancing Lactate Content and MCT2 Expression in APP/PS1 Transgenic Mouse Model of Alzheimer's Disease. Anat Rec (Hoboken). 2019;302(2):332-8.

262. Sun Z-Z, Li X-Y, Wang S, Shen L, Ji H-F. Bidirectional interactions between curcumin and gut microbiota in transgen- ic mice with Alzheimer's disease. Applied Microbiology and Biotechnology. 2020;104(8):3507-15.

263. Singh A, Tripathi $P$, Yadawa AK, Singh S. Promising Polyphenols in Parkinson's Disease Therapeutics. Neurochem Res. 2020;45(8):1731-45.

264. Muthian G, Mackey V, Prasad K, Charlton C. Curcumin and an antioxidant formulation protect $\mathrm{C} 57 \mathrm{BL} / 6 \mathrm{~J}$ mice from MPTP-induced Parkinson's disease like changes: potential neuroprotection for neurodegeneration. Journal of Parkinsonism and Restless Legs Syndrome. 2018;8:49-59.

265. Wu Y, Liang $S, X u B$, Zhang $R, X u$ L. Protective effect of curcumin on dopamine neurons in Parkinson's disease and its mechanism. Zhejiang da xue xue bao Yi xue ban = Journal of Zhejiang University Medical sciences. 2018;47(5):480-6.

266. Wang YL, Liu XS, Wang SS, et al. Curcumin-Activated Mesenchymal Stem Cells Derived from Human Umbilical Cord and Their Effects on MPTP-Mouse Model of Parkinson's Disease: A New Biological Therapy for Parkinson's Disease. Stem Cells International. 2020;2020.

267. El Nebrisi E, Javed H, Ojha SK, Oz M, Shehab S. Neuroprotective Effect of Curcumin on the Nigrostriatal Pathway in a 6-Hydroxydopmine-Induced Rat Model of Parkinson's Disease is Mediated by alpha 7-Nicotinic Receptors. International Journal of Molecular Sciences. 2020;21(19).

268. Ryu YK, Park HY, Go J, Kim YH, et al. Effects of histone acetyltransferase inhibitors on I-DOPA-induced dyskinesia in a murine model of Parkinson's disease. Journal of Neural Transmission. 2018;125(9):1319-31.

269. Moosavi M, Farrokhi MR, Tafreshi N. The effect of curcumin against 6-hydroxydopamine induced cell death and Akt/ GSK disruption in human neuroblastoma cells. Physiology and Pharmacology (Iran). 2018;22(3):163-71. 
270. Abbaoui A, Gamrani H. Neuronal, astroglial and locomotor injuries in subchronic copper intoxicated rats are repaired by curcumin: A possible link with Parkinson's disease. Acta Histochemica. 2018;120(6):542-50.

271. Laabbar W, Elgot A, Elhiba O, Gamrani $\mathrm{H}$. Curcumin prevents the midbrain dopaminergic innervations and locomotor performance deficiencies resulting from chronic aluminum exposure in rat. Journal of Chemical Neuroanatomy. 2019;100.

272. Khodadadi $H$, Jahromi GP, Zaeinalifard G, Fasihi-Ramandi M, Esmaeili M, Shahriary A. Neuroprotective and Antiapoptotic Effects of Allopregnanolone and Curcumin on Arsenic-Induced Toxicity in SH-SY5Y Dopaminergic Human Neuroblastoma Cells. Neurophysiology. 2020;52(2):124-33.

273. Mirakabad FST, Khoramgah MS, Tahmasebinia F, Darabi S, Abdi S, Abbaszadeh HA, Khoshsirat S. The Effect of Low-Level Laser Therapy and Curcumin on the Expression of LC3, ATG10 and BAX/BCL2 Ratio in PC12 Cells Induced by 6-Hydroxide Dopamine. Journal of Lasers in Medical Sciences. 2020;11(3):299-304.

274. Nguyen TT, Vuu MD, Huynh MA, Yamaguchi M, Tran LT, Dang TPT. Curcumin Effectively Rescued Parkinson's Disease-Like Phenotypes in a Novel Drosophila melanogaster Model with dUCH Knockdown. Oxidative Medicine and Cellular Longevity. 2018;2018.

275. Buratta S, Chiaradia E, Tognoloni A, et al. Effect of Curcumin on Protein Damage Induced by Rotenone in Dopaminergic PC12 Cells. International Journal of Molecular Sciences. 2020;21(8).

276. Sharma N, Nehru B. Curcumin affords neuroprotection and inhibits $\alpha$-synuclein aggregation in lipopolysaccharide-induced Parkinson's disease model. Inflammopharmacology. 2018;26(2):349-60.
277. Qiao PF, Ma JX, Wang YY, et al. Curcumin Prevents Neuroinflammation by Inducing Microglia to Transform into the M2-phenotype via CaMKK beta-dependent Activation of the AMP-Activated Protein Kinase Signal Pathway. Current Alzheimer Research. 2020;17(8):735-52.

278. Motawi TK, Sadik NAH, Hamed MA, Ali SA, Khalil WKB, Ahmed YR. Potential therapeutic effects of antagonizing adenosine $A 2 A$ receptor, curcumin and niacin in rotenone-induced Parkinson's disease mice model. Molecular and Cellular Biochemistry. 2020;465(1-2):89-102.

279. Dehghani $Z$, Meratan AA, Saboury AA, Nemat-Gorgani M. $\alpha$-Synuclein fibrillation products trigger the release of hexokinase I from mitochondria: Protection by curcumin, and possible role in pathogenesis of Parkinson's disease. Biochim Biophys Acta Biomembr. 2020;1862(6):183251.

280. Kamelabad MR, Sardroodi JJ, Ebrahimzadeh AR. The Interaction of Curcumin and Rosmarinic Acid with Non-Amyloid-Component Domain of Alpha-Synuclein: A Molecular Dynamics Study. Chemistryselect. 2020;5(11):3312-20.

281. Doytchinova I, Atanasova M, Salamanova $E$, Ivanov S, Dimitrov I. Curcumin inhibits the primary nucleation of amyloid-beta peptide: A molecular dynamics study. Biomolecules. 2020;10(9):1-14.

282. Maiti P, Dunbar GL. Use of Curcumin, a Natural Polyphenol for Targeting Molecular Pathways in Treating Age-Related Neurodegenerative Diseases. International Journal of Molecular Sciences. 2018;19(6).

283. Liu S, Li X. Regulation of Autophagy in Neurodegenerative Diseases by Natural Products. Adv Exp Med Biol. 2020;1207:725-30.

284. Ghasemi F, Bagheri H, Barreto GE, Read MI, Sahebkar A. Effects of Curcumin on Microglial Cells. Neurotox Res. 2019;36(1):12-26. 
285. Bagheri H, Ghasemi F, Barreto GE, Rafiee R, Sathyapalan T, Sahebkar A. Effects of curcumin on mitochondria in neurodegenerative diseases. Biofactors. 2020;46(1):5-20.

286. Labanca F, Ullah $\mathrm{H}$, Khan $\mathrm{H}$, et al. Therapeutic and Mechanistic effects of Curcumin in Huntington's disease. Curr Neuropharmacol. 2020.

287. Tang Y. Editorial: Microglial polarization in the pathogenesis and therapeutics of neurodegenerative diseases. Frontiers in Aging Neuroscience. 2018;10(MAY).

288. Tewari D, Stankiewicz AM, Mocan A, et al. Ethnopharmacological Approaches for Dementia Therapy and Significance of Natural Products and Herbal Drugs. Frontiers in Aging Neuroscience. 2018;10.

289. Uddin MS, Al Mamun A, Kabir MT, et al. Neuroprotective role of polyphenols against oxidative stress-mediated neurodegeneration. European Journal of Pharmacology. 2020;886.

290. Yeung AWK, Tzvetkov NT, Georgieva $M G$, et al. Reactive Oxygen Species and Their Impact in Neurodegenerative Diseases: Literature Landscape Analysis. Antioxidants and Redox Signaling. 2021;34(5):402-20.

291. Sharma V, Ghosh KS. Inhibition of Amyloid Fibrillation by Small Molecules and Nanomaterials: Strategic Development of Pharmaceuticals Against Amyloidosis. Protein and Peptide Letters. 2019;26(5):315-23.

292. Elifani F, Castaldo S, Capocci L et al. Curcumin-supplemented diet preserves body weight and ameliorates intestinal functionality in R6/2 mice. Journal of Neurology, Neurosurgery and Psychiatry. 2018;89:A94-A5.

293. Beasley M, Stonebraker AR, Hasan I, et al. Lipid Membranes Influence the Ability of Small Molecules To Inhibit Huntingtin Fibrillization. Biochemistry. 2019;58(43):4361-73.
294. Maity D, Rajendra Sandur V. An updated review on herbal drugs: Nootropic activity and possible mechanisms. Asian Journal of Pharmaceutical and Clinical Research. 2019;12(6):19-26.

295. Chowdhury S, Kumar S. Bioactive Phytocompounds: Anti-amyloidogenic Effects Against Hen Egg-White Lysozyme Aggregation. Protein Journal. 2021;40(1):78-86.

296. Pepe G, Calce E, Verdoliva V, et al. Curcumin-loaded nanoparticles based on amphiphilic hyaluronan-conjugate explored as targeting delivery system for neurodegenerative disorders. International Journal of Molecular Sciences. 2020;21(22):1-13.

297. Gharaibeh A, Maiti P, Culver R, et al. Solid Lipid Curcumin Particles Protect Medium Spiny Neuronal Morphology, and Reduce Learning and Memory Deficits in the YAC128 Mouse Model of Huntington's Disease. International Journal of Molecular Sciences. 2020;21(24).

298. Khyati, Malik I, Agrawal N, Kumar V. Melatonin and curcumin reestablish disturbed circadian gene expressions and restore locomotion ability and eclosion behavior in Drosophila model of Huntington's disease. Chronobiology international. 2021;38(1):61-78.

299. Kukkemane K, Jagota A. Therapeutic effects of curcumin on age-induced alterations in daily rhythms of clock genes and Sirt1 expression in the SCN of male Wistar rats. Biogerontology. 2019;20(4):405-19.

300. Qureshi M, Al-Suhaimi EA, Wahid F, Shehzad $O$, Shehzad A. Therapeutic potential of curcumin for multiple sclerosis. Neurological Sciences. 2018;39(2):207-14.

301. Esmaeilzadeh E, Soleimani M, Zare-Abdollahi D, Jameie B, Khorshid HRK. Curcumin ameliorates experimental autoimmune encephalomyelitis in a C57BL/6 mouse model. Drug Development Research. 2019;80(5):629-36. 
302. Boyao Y, Mengjiao S, Caicai B, Xiaoling $L$, Zhenxing L, Manxia W. Dynamic expression of autophagy-related factors in autoimmune encephalomyelitis and exploration of curcumin therapy. J Neuroimmunol. 2019;337:577067.

303. Motavaf $M$, Sadeghizadeh $M$, Babashah S, Zare L, Javan M. Protective Effects of a Nano-Formulation of Curcumin against Cuprizone-Induced Demyelination in the Mouse Corpus Callosum. Iran J Pharm Res. 2020;19(3):310-20.

304. Motavaf M, Sadeghizadeh M, Babashah S, Zare L, Javan M. Dendrosomal nanocurcumin promotes remyelination through induction of oligodendrogenesis in experimental demyelination animal model. J Tissue Eng Regen Med. 2020;14(10):1449-64.

305. Liu JQ, Yan YQ, Liu JT, Wang YR, Wang $X$. Curcumin prevents experimental autoimmune encephalomyelitis by inhibiting proliferation and effector CD4+ $\mathrm{T}$ cell activation. Eur Rev Med Pharmacol Sci. 2019;23(20):9108-16.

306. Ulamek-Koziol M, Czuczwar SJ, Januszewski S, Pluta R. Substantiation for the Use of Curcumin during the Development of Neurodegeneration after Brain Ischemia. Int J Mol Sci. 2020;21(2).

307. Xie CJ, Gu AP, Cai J, Wu Y, Chen RC. Curcumin protects neural cells against ischemic injury in N2a cells and mouse brain with ischemic stroke. Brain and Behavior. 2018;8(2).

308. Zhang Y, Fang M, Sun YM, et al. Curcumin attenuates cerebral ischemia injury in Sprague-Dawley rats and PC12 cells by suppressing overactivated autophagy. Journal of Photochemistry and Photobiology B-Biology. 2018;184:1-6.

309. Xu L, Ding L, Su Y, Shao R, Liu J, Huang Y. Neuroprotective effects of curcumin against rats with focal cerebral ischemia-reperfusion injury. Int J Mol Med. 2019;43(4):1879-87.
310. Mo Y, Yue EL, Shi N, Liu KY. The protective effects of curcumin in cerebral ischemia and reperfusion injury through PKC-theta signaling. Cell Cycle. 2021.

311. Wu L, Jiang $C$, Kang $Y$, Dai $Y$, Fang $W$, Huang P. Curcumin exerts protective effects against hypoxiareoxygenation injury via the enhancement of apurinic/apyrimidinic endonuclease 1 in SHSY5Y cells: Involvement of the PI3K/AKT pathway. Int J Mol Med. 2020;45(4):993-1004.

312. Huang LF, Chen CW, Zhang $X$, Li $X$, et al. Neuroprotective Effect of Curcumin Against Cerebral Ischemia-Reperfusion Via Mediating Autophagy and Inflammation. Journal of Molecular Neuroscience. 2018;64(1):129-39.

313. Hussein YA, Al-sarraf AM, Alfalluji WL. Modulation of oxidative stress, inflammatory and apoptotic response by curcumin against cerebral ischemia reperfusion injury in a mouse model. Interdisciplinary Neurosurgery: Advanced Techniques and Case Management. 2020;21.

314. Lu ZY, Liu YP, Shi Y, et al. Curcumin protects cortical neurons against oxygen and glucose deprivation/reoxygenation injury through flotillin-1 and extracellular signal-regulated kinase1/2 pathway. Biochemical and Biophysical Research Communications. 2018;496(2):515-22.

315. Wang Z, Ren W, Zhao F, Han Y, Liu C, Jia K. Curcumin amends $\mathrm{Ca}(2+)$ dysregulation in microglia by suppressing the activation of P2X7 receptor. Mol Cell Biochem. 2020;465(1-2):65-73.

316. Cai L, Li WT, Zhang LL, Lu XQ, Chen $M$, Liu Y. Long noncoding RNA GAS5 enhanced by curcumin relieves poststroke depression by targeting miR-10b/BDNF in rats. J Biol Regul Homeost Agents. 2020;34(3):815-23.

317. Buratti E. Targeting TDP-43 proteinopathy with drugs and drug-like small molecules. British Journal of Pharmacology. 2021;178(6):1298-315. 
318. Duan W, Guo Y, Xiao J, et al. Neuroprotection by monocarbonyl dimethoxycurcumin $\mathrm{C}$ : ameliorating the toxicity of mutant TDP-43 via HO-1. Mol Neurobiol. 2014;49(1):368-79.

319. Dhir A. Curcumin in epilepsy disorders. Phytother Res. 2018;32(10):1865-75.

320. Kumar V, Prakash C, Singh R, Sharma D. Curcumin's antiepileptic effect, and alterations in $\mathrm{Na}(\mathrm{v}) 1.1$ and $\mathrm{Na}(\mathrm{v}) 1.6$ expression in iron-induced epilepsy. Epilepsy Res. 2019;150:7-16.

321. Kumar P, Sharma D. Ameliorative effect of curcumin on altered expression of CACNA1A and GABRD in the pathogenesis of $\mathrm{FeCl}(3)$-induced epilepsy. Mol Biol Rep. 2020;47(8):5699-710.

322. Mansoor SR, Hashemian M, Khalili-Fomeshi M, Ashrafpour M, Moghadamnia AA, Ghasemi-Kasman M. Upregulation of klotho and erythropoietin contributes to the neuroprotection induced by curcumin-loaded nanoparticles in experimental model of chronic epilepsy. Brain Research Bulletin. 2018;142:281-8.

323. Huang $R Q$, Zhu $Y J$, Lin LJ, Song SM, Cheng LM, Zhu RR. Solid Lipid Nanoparticles Enhanced the Neuroprotective Role of Curcumin against Epilepsy through Activation of $\mathrm{Bcl}-2$ Family and P38 MAPK Pathways. Acs Chemical Neuroscience. 2020;11(13):1985-95.

324. Hodges SL, Lugo JN. Therapeutic role of targeting mTOR signaling and neuroinflammation in epilepsy. Epilepsy Research. 2020;161.

325. Bertoncello KT, Aguiar GPS, Oliveira JV, Siebel AM. Micronization potentiates curcumin's anti-seizure effect and brings an important advance in epilepsy treatment. Sci Rep. 2018;8(1):2645.

326. Vollono L, Falconi M, Gaziano R, lacovelli F, Dika E, Terracciano C, Bianchi L, Campione E. Potential of Curcumin in Skin Disorders. Nutrients. 2019;11(9).

327. Kang NW, Kim MH, Sohn SY, et al. Curcumin-loaded lipid-hybridized cellulose nanofiber film ameliorates imiquimod-induced psoriasis-like dermatitis in mice. Biomaterials. 2018;182:245-58.

328. Filippone A, Consoli GML, Granata G, et al. Topical Delivery of Curcumin by Choline-Calix[4]arene-Based Nanohydrogel Improves Its Therapeutic Effect on a Psoriasis Mouse Model. Int J Mol Sci. 2020;21(14).

329. Jin N, Lin J, Yang C, et al. Enhanced penetration and anti-psoriatic efficacy of curcumin by improved smartPearls technology with the addition of glycyrrhizic acid. Int J Pharm. 2020;578:119101.

330. Li F, Shi Y, Liang J, Zhao L. Curcumin-loaded chitosan nanoparticles promote diabetic wound healing via attenuating inflammation in a diabetic rat model. J Biomater Appl. 2019;34(4):476-86.

331. Deng $X$, Li F, Li Y, et al. Effect of curcumin on wound healing in a murine model of diabetic foot. J Biol Regul Homeost Agents. 2020;34(5):1879-84

332. Ghufran $\mathrm{H}$, Mehmood A, Azam M, et al. Curcumin preconditioned human adipose derived stem cells co-transplanted with platelet rich plasma improve wound healing in diabetic rats. Life Sci. 2020;257:118091.

333. Kallis PJ, Price A, Dosal JR, Nichols AJ, Keri J. A Biologically Based Approach to Acne and Rosacea. J Drugs Dermatol. 2018;17(6):611-7.

334. Madan S, Nehate C, Barman TK, Rathore AS, Koul V. Design, preparation, and evaluation of liposomal gel formulations for treatment of acne: in vitro and in vivo studies. Drug Dev Ind Pharm. 2019;45(3):395-404.

335. Soleymani $\mathrm{S}$, Farzaei $\mathrm{MH}$, Zargaran A, Niknam S, Rahimi R. Promising plant-derived secondary metabolites for treatment of acne vulgaris: a mechanistic review. Arch Dermatol Res. 2020;312(1):5-23.

336. Khan M, Nadhman A, Sehgal SA, Siraj $S$, Yasinzai MM. Formulation and Char- 
acterization of a Self-Emulsifying Drug Delivery System (SEDDS) of Curcumin for the Topical Application in Cutaneous and Mucocutaneous Leishmaniasis. Curr Top Med Chem. 2018;18(18):1603-9.

337. Di Nardo $V$, Barygina $V$, Franca K, Tirant $M$, Valle $Y$, Lotti T. Functional nutrition as integrated approach in vitiligo management. Dermatol Ther. 2019;32(4):e12625.
338. Adusumilli NC, Mordorski B, Nosanchuk J, Friedman JM, Friedman AJ. Curcumin nanoparticles as a photoprotective adjuvant. Exp Dermatol. 2021.

339. Liu X, Zhang R, Shi H, Li X, Li Y, Taha A, Xu C. Protective effect of curcumin against ultraviolet $A$ irradiationinduced photoaging in human dermal fibroblasts. Mol Med Rep. 2018;17(5):7227-37. 